\title{
UN BUEN INSTRUMENTO PARA LA TUTELA DEL CRÉDITO QUE SUSCITA NO POCOS PROBLEMAS PRÁCTICOS: EL PROCESO EUROPEO DE ESCASA CUANTÍA*
}

\author{
A GOOD INSTRUMENT FOR THE PROTECTION OF CREDIT \\ THAT RAISES SOME PRACTICAL PROBLEMS: \\ THE EUROPEAN SMALL CLAIM PROCEDURE**
}

\author{
JuLIo SigÜENZA LÓPEZ \\ Profesor Titular de Derecho Procesal \\ Universidad de Murcia \\ ORCID ID: 0000-0003-0462-2635
}

Recibido: 18.06.2021/ Aceptado: 06.07.2021

DOI: https://doi.org/10.20318/cdt.2021.6270

\begin{abstract}
Resumen: En el presente estudio se analiza el proceso europeo de escasa cuantía, instrumento con el que se pretende favorecer el cobro de créditos transfronterizos que no excedan de 5.000 euros que, pese a su sencillez, o quizá precisamente por ella, presenta no pocos problemas prácticos. Se articula sobre la base de formularios estandarizados, sin que sea necesario que intervengan profesionales del Derecho, desarrollándose fundamentalmente por escrito, aun cuando se prevé la posibilidad de que las pruebas puedan practicarse en una audiencia a través de videoconferencia u otros sistemas de comunicación, lo que puede poner en entredicho las garantías inherentes a la oralidad, singularmente la de la inmediación. El hecho de que la sentencia que le ponga fin pueda ejecutarse directamente en cualquier Estado de la Unión Europea que haya suscrito el Reglamento comunitario 861/2007 constituye uno de sus principales atractivos, siendo preciso potenciar sus restantes alicientes si se desea un uso más efectivo del mismo.

Palabras clave: tutela del crédito, proceso europeo de escasa cuantía.
\end{abstract}

\begin{abstract}
This study analyzes the European small-amount process, an instrument which intendeds to favor the collection of cross-border credits not exceeding 5.000 euros which, despite its simplicity, or perhaps precisely because of it, presents many problems practical. It is based on standardized forms, without needing the intervention of legal professionals, thus being developed mainly in written. Nevertheless, it is foreseen the possibility is foreseen that the evidence can be practiced in a hearing through videoconference or other communication systems, even though it can call into question the guarantees inherent to orality, particularly that of immediacy. The fact that the sentence that puts an end to it can be executed directly in any State of the European Union that has signed Community Regulation 861/2007 is one of its main attractions, being necessary to enhance the other incentives whether a more effective use is desired.
\end{abstract}

Keywords: credit protection, European small claims process.

${ }^{*}$ El presente trabajo se ha realizado en el marco del Proyecto de Investigación «Proceso, métodos complementarios o alternativos y nuevas tecnologías para una justicia más garantista: los retos pendientes en la tutela jurisdiccional» (DER201785675-R), financiado por MINECO/AEI/FEDER, UE.

This work has been carried out within the framework of the Research Project "Process, complementary or alternative methods and new technologies for a more guaranteeist justice: pending challenges in judicial protection" (DER2017-85675-R), funded by MINECO / AEI / ERDF, EU. 
Sumario: I. Presentación. II. Objeto y ámbito de aplicación. III. Peculiaridades que lo singularizan. IV. Procedimiento. A) Demanda. B) Examen de la demanda y, en su caso, admisión a trámite. C) Traslado de la demanda al demandado. D) Posibles conductas del demandado frente a la demanda. E) Actuaciones posteriores y dictado de la sentencia. V. Posibles recursos contra la sentencia. VI. Reconocimiento y ejecución de sentencias en otro Estado de la Unión Europea que haya suscrito el Reglamento comunitario 861/2007. VII. Cuestiones a considerar.

\section{Presentación}

1. Como es sabido, la Unión Europea es una asociación política y económica, constituida por 27 países tras la salida del Reino Unido, que han delegado parte de su soberanía en distintas instituciones comunes para que estas adopten democráticamente decisiones sobre asuntos de interés para todos ellos.

2. Es igualmente conocido que, en los últimos años, la Unión Europea ha realizado un importante esfuerzo por regular procesos que puedan ser utilizados por todos los ciudadanos que la integran, a fin de facilitar su acceso a la Justicia.

3. Así,

- con el deseo de acelerar y simplificar que pueda ejecutarse en un Estado de la Unión distinto de aquel en que se dictó la resolución acordada contra un deudor o un documento ejecutivo que requiera el consentimiento expreso de este, ya sea una transacción judicial o un documento público con fuerza ejecutiva, el 21 de abril de 2004, el Parlamento Europeo y el Consejo de la Unión Europea aprobaron el Reglamento (CE) núm. 805/2004, por el que se establece un título ejecutivo europeo para créditos no impugnados;

- con el fin de simplificar, acelerar y reducir los costes de litigación en asuntos transfronterizos relativos a créditos pecuniarios no impugnados, el 12 de diciembre de 2006, el Parlamento Europeo y el Consejo de la Unión Europea aprobaron el Reglamento (CE) núm. 1896/2006, por el que se establece un proceso monitorio europeo;

- con el propósito de establecer normas comunes que permitan simplificar y acelerar los litigios transfronterizos referidos a las demandas de pensión alimenticia, el 18 de diciembre de 2008, el Consejo de la Unión Europea aprobó el Reglamento núm. 4/2009, relativo a la competencia, la ley aplicable, el reconocimiento y la ejecución de las resoluciones y la cooperación en materia de obligaciones de alimentos;

- con la intención de suprimir los obstáculos que puedan existir para que los ciudadanos de la Unión puedan ejercer sus derechos en situaciones de sucesión mortis causa con repercusiones transfronterizas; y, más en concreto, para que puedan organizar su sucesión y puedan garantizarse eficazmente los derechos de los herederos y legatarios y de las personas próximas al causante, así como de los acreedores de la herencia, el 4 de julio de 2012, el Parlamento Europeo y el Consejo de la Unión Europea aprobaron el Reglamento (UE) núm. 650/2012, relativo a la competencia, la ley aplicable, el reconocimiento y la ejecución de las resoluciones, a la aceptación y la ejecución de los documentos públicos en materia de sucesiones mortis causa y a la creación de un certificado sucesorio europeo.

4. De igual modo, con la voluntad de simplificar y acelerar los litigios de escasa cuantía económica en determinados asuntos civiles y mercantiles de carácter transfronterizo, el 11 de julio de 2007, el Parlamento Europeo y el Consejo de la Unión Europea aprobaron el Reglamento (CE) núm. 861/2007, por el que se establece un proceso europeo de escasa cuantía, que es el que va a ocupar nuestra atención a partir de ahora.

5. Según se dice en sus considerandos iniciales, con dicho Reglamento se pretenden dos grandes objetivos: regular un proceso europeo que, sin merma de las debidas garantías, facilite la resolución 
de determinados asuntos patrimoniales de carácter transnacional ${ }^{1}$; y eliminar cualquier procedimiento intermedio que pueda existir para que las sentencias dictadas en un país integrante de la Unión, tras el desarrollo de este proceso, pueda ejecutarse en otro distinto a aquel en que se hayan acordado ${ }^{2}$.

6. Con todo, la realidad pone de manifiesto que, al menos en nuestro país, es un proceso escasamente conocido y, por ende, poco utilizado.

Nuestra afirmación se basa en la información que facilita el Centro de Documentación Judicial (CENDOJ), que no registra ningún resultado cuando se consulta los procesos europeos de escasa cuantía tramitados por Juzgados de Primera Instancia o por Juzgados de Primera Instancia e Instrucción y solo facilita 54 resultados de casos tramitados por Juzgados de lo Mercantil, la gran mayoría referidos a reclamaciones en materia de transporte, sobre todo aéreo, como consecuencia de retrasos en el vuelo contratado, pérdidas de enlace con otros viajes, extravío de equipajes, etcétera ${ }^{3}$.

7. Lo anterior permite alcanzar una primera conclusión. En realidad, dos. Que es necesario que se dé a conocer más el derecho procesal civil europeo y su importancia para resolver determinadas disputas. Y que los juristas hemos de profundizar en su estudio -más de lo que ya lo hacemos-y formular propuestas para que aquel pueda ser más eficaz, ampliando así nuestro espectro de análisis, en beneficio del conjunto de la sociedad.

\section{Objeto y ámbito de aplicación}

8. El proceso europeo para demandas de escasa cuantía -más conocido como «proceso europeo de escasa cuantía»- es un instrumento opcional que se añade a los ya existentes en nuestro ordenamiento que, como hemos señalado, nace con dos principales propósitos: el de simplificar y acelerar los litigios de escasa cuantía económica en asuntos transfronterizos; y el de reducir los costes que dichos juicios llevan consigo, eliminando los obstáculos que puedan impedir que se reconozcan en un Estado de la Unión Europea las sentencias dictadas por los órganos jurisdiccionales de otro Estado miembro al resolver esta clase de litigios (cfr. el art. 1 del Reglamento (CE) núm. 861/2007, del Parlamento Europeo y del Consejo, de 11 de julio [en adelante, el Reglamento o el RPEEC]).

9. Se rige por lo dispuesto en el RPEEC y, con carácter supletorio, en lo que no se encuentre regulado por este, por la legislación procesal del Estado en el que se desarrolle (vid. su art. 19) ${ }^{4}$. En nuestro caso, por la Ley de Enjuiciamiento Civil (LECiv, en lo sucesivo).

Dicho esto, debe apuntarse de inmediato que dicha norma comunitaria ha sido objeto de dos reformas: una en 2015, por la que se elevó de 2.000 a 5.000 euros el valor económico de la demanda que puede formularse; y otra en 2017, en virtud de la cual se actualizaron los cuatro formularios que se acompañan a la misma como anexos, a fin de contuviesen las modificaciones que se aprobaron en 2015 y debían entrar en vigor el 14 de julio de 2017.

Y también, claro está, que nuestra LECiv ha sido modificada en dos ocasiones en cuestiones que afectan al proceso europeo de escasa cuantía. En virtud de la Ley 4/2011, de 24 de marzo, que incorporó a la misma su actual disposición final vigésima cuarta, que tiene la significativa rúbrica de «Medidas para facilitar la aplicación en España del Reglamento (CE) $n .^{\circ} 861 / 2007$ del Parlamento Europeo y del Consejo, de 11 de julio de 2007, por el que se establece un proceso europeo de escasa cuantía». Y por medio de la Ley 37/2011, de 10 de octubre, de medidas de agilización procesal, que reformó su artículo 455.1, con las consecuencias que posteriormente veremos.

\footnotetext{
${ }^{1}$ Cfr. los artículos 1 a 19 del Reglamento (CE) núm. 861/2007, del Parlamento Europeo y del Consejo, de 11 de julio de 2007, por el que se establece un proceso europeo de escasa cuantía («Diario Oficial de la Unión Europea», núm. 199, de 31 de julio de 2007, págs. 1 a 22).

${ }^{2}$ Vid. los artículos 20 a 23 del Reglamento arriba mencionado.

${ }^{3}$ Datos a 28 de mayo de 2021. Sobre este particular, véase lo que se dice más adelante en el último apartado de este estudio.

${ }^{4}$ Por tanto, la regulación que se hace en el RPEEC se ciñe a sus elementos esenciales, no es exhaustiva.
} 
10. La lectura atenta de lo dispuesto en el RPEEC pone de manifiesto que nos encontramos ante un proceso aplicable en todos los Estados de la Unión Europea, salvo en Dinamarca (art. 2.3), debido a las salvedades con que dicho país se adhirió al Tratado de Ámsterdam ${ }^{5}$, que permite discutir algunas cuestiones civiles y mercantiles en asuntos transfronterizos cuando el valor económico de la demanda no exceda de $5.000 €^{6}$, excluido el importe de los posibles intereses, gastos y costas ${ }^{7}$.

Ello implica una primera conclusión: la de que no puede utilizarse cuando el valor económico del litigio supere dicho importe o la cuantía sea indeterminada, hipótesis en las que solo podrán utilizarse los cauces procesales que, en su caso, prevea cada derecho interno.

Sin embargo, no supone que solo esté pensado para reclamar deudas dinerarias. En absoluto. Pues también puede utilizarse para ejercitar pretensiones de condena no pecuniarias (relativas a un hacer, a un no hacer o a la entrega de una cosa distinta a dinero $)^{8}$, o incluso, aunque seguramente serán más infrecuentes, pretensiones meramente declarativas o constitutivas (por ejemplo, la petición de que se anule un contrato), siempre y cuando, eso sí, se cumpla el presupuesto antes reseñado de que la cuantía del pleito no sobrepase la suma de 5.000 euros $^{9}$. Así se deduce del formulario de demanda que figura como anexo I en el RPPEC.

Nada dispone el Reglamento sobre cómo debe determinarse la cuantía en estos casos. Por lo que ha de estarse a lo que disponga cada ordenamiento interno, y, por lo que hace a nuestro país, a lo previsto en los artículos 251 y siguientes de la LECiv.

11. Sentado lo anterior, conviene aclarar de inmediato dos aspectos relacionados con el que acaba de señalarse. Pues es preciso saber cuándo se entiende que estamos ante un asunto civil o mercantil de los que puede discutirse a través de este proceso y cuándo se considera que estamos ante un asunto transfronterizo.

12. En relación con la primera cuestión, ha de apuntarse que el RPEEC, en lugar de ofrecer un elenco de asuntos de carácter civil y mercantil a los que resulta de aplicación el proceso que regula, opta por la solución contraria, señalando aquellas materias que quedan excluidas de su aplicación.

$\mathrm{Y}$, así, refiere que sus disposiciones no son aplicables a asuntos que versen sobre materia fiscal, aduanera y administrativa; a aquellos en que se reclame responsabilidad a un Estado por acciones u omisiones en el ejercicio de su autoridad; ni a los que se refieran al estado y capacidad jurídica de las personas físicas, a los derechos de propiedad derivados de los regímenes matrimoniales o de los regímenes que regulen cuestiones con efectos comparables al matrimonio según la ley aplicable a dichas relaciones, a las obligaciones de alimentos derivadas de relaciones de familia, parentesco, matrimonio o afinidad, a los testamentos y sucesiones, incluidas las obligaciones de alimentos por causa de muerte, a la quiebra, los procedimientos de liquidación de empresas o de otras personas jurídicas insolventes, los convenios entre quebrado y acreedores y demás procedimientos análogos, a la seguridad social, al arbitraje, al derecho laboral, a los arrendamientos de inmuebles, excepto las acciones sobre derechos pecuniarios, o a las violaciones del derecho a la intimidad y de los derechos de la personalidad, incluida la difamación ${ }^{10}$.

\footnotetext{
${ }^{5}$ En efecto. Dinamarca, al no participar en la aprobación de ningún reglamento comunitario, salvo que expresamente salve la excepción que a tal efecto formuló en su día, no se encuentra vinculado por el RPEEC, ni está sujeto a su aplicación.

${ }^{6}$ La suma de 5.000 euros puede parece insuficiente en aquellos casos en los que la legislación nacional regula algún proceso de escasa cuantía para reclamar cantidades superiores a la ya señalada, pero ha de tenerse en cuenta la dispar realidad jurídica y económica de los distintos países que integran la llamada Unión Europea, lo que no facilita el necesario consenso para que pueda elevarse dicho umbral en un futuro próximo.

${ }^{7}$ Estas partidas no se tienen en cuenta para fijar el valor del litigio, pero, no obstante, pueden reclamarse en él (vid. el Considerando 10 del RPEEC y el formulario oficial de demanda).

${ }^{8}$ Vid. a este respecto el artículo 5.5 del RPEEC.

${ }^{9}$ A juicio de VAlencia Mirón, dicho límite hace referencia a la cuantificación de la pretensión íntegra, por lo que, de acuerdo con dicho criterio, se vulneraría el Reglamento (CE) núm. 861/2007 si se interpusieran dos o más demandas que formalmente no excedieran del mismo para reclamar una deuda superior a 5.000 euros (A. VALENCIA MIRÓN, «El proceso europeo de escasa cuantía», en Derecho Procesal Civil Europeo. Vol. III. Tutela judicial del crédito en la Unión Europea [dirigido por Andrés de la Oliva Santos; coordinado por Carmen Senés Motilla y Jaime Vegas Torres], Thomson Reuters (Legal) Limited, Cizur Menor, 2011, pág. 267).

${ }^{10}$ Cfr. su artículo 2.
} 
Lo que permite concluir -con VALENCIA MiRÓN- que la «materia civil y mercantil» a que se refiere la norma se identifica con el llamado derecho privado patrimonial ${ }^{11}$. Y, lo que es más importante, por lo que ahora nos interesa, que pese a lo que pueda sugerir su rúbrica, a través de este reglamento comunitario no pueden reclamarse todas las deudas de pequeña cuantía en asuntos europeos o supranacionales: se trata de un cauce que solo puede ser utilizado para ejercitar acciones en determinados asuntos de carácter privado, civil o mercantil, siempre y cuando, además, el valor económico de la demanda no exceda del umbral económico antedicho de 5.000€.

13. Por lo que hace a la segunda, el legislador comunitario ha dispuesto que, a los efectos de este Reglamento, son asuntos transfronterizos aquellos en los que, al menos una de las partes, esté domiciliada o tenga su residencia habitual en un Estado miembro distinto de aquel al que pertenezca el tribunal que conozca del conflicto. Lo que, como es lógico, requiere determinar con carácter previo en qué casos se está domiciliado en el Estado cuyos órganos jurisdiccionales conocen del asunto, cuestión a la que dan respuesta los artículos 62 y 63 del Reglamento (UE) núm. 1215/2012, del Parlamento Europeo y del Consejo, de 12 de diciembre de 2012, relativo a la competencia judicial, el reconocimiento y la ejecución de resoluciones judiciales en materia civil y mercantil.

De acuerdo con dichos preceptos, para determinar si una parte está domiciliada en el Estado cuyos tribunales conocen el asunto, estos han de tener en consideración su ley nacional, aplicando la de otro país de la Unión Europea solo cuando no esté domiciliada en aquel y sea preciso determinar si lo está en este, entendiéndose, a los efectos de dicho Reglamento, que una sociedad o persona jurídica está domiciliada en el lugar en que se encuentra su sede estatutaria, su administración central o su centro de actividad principal, y que un trust está domiciliado en el Estado miembro cuyos tribunales conocen del asunto si así lo determinan sus normas de Derecho internacional privado.

\section{Peculiaridades que lo singularizan}

14. Una vez aclarado que estamos ante un proceso que complementa los existentes en cada ordenamiento interno, en virtud del cual pueden reclamarse determinadas cuestiones civiles y mercantiles en asuntos transfronterizos cuando el valor económico del litigio no exceda de 5.000 euros, procede destacar dos notas que lo singularizan.

15. En primer lugar, la de que el proceso europeo de escasa cuantía se desarrolla de forma predominantemente escrita (art. 5.1 del Reglamento), lo que resulta absolutamente lógico, habida cuenta que se ha articulado en la idea de que, al menos una de las partes, no va a estar físicamente presente en el lugar donde se va a desarrollar.

Ello no supone que el tribunal que conozca del mismo no pueda ordenar la celebración de una vista oral -que, en su caso, podrá celebrarse por videoconferencia u otros medios de comunicación, en la medida en que se disponga de los medios técnicos correspondientes (art. 8.1 del RPEEC)-. En absoluto. Puede hacerlo en dos concretos supuestos: cuando considere que es necesaria y cuando, habiéndola solicitado una de las partes, no la estime inconveniente a la vista de las circunstancias que concurran en el caso de que se trate.

Por tanto, puede acordarse. Y, además, si se piensa con sosiego, y por tanto con método y orden, es lógico que pueda hacerse. Pues, en ocasiones, es evidente que puede ayudar a delimitar las cuestiones objeto de debate.

Ahora bien, habida cuenta la decidida apuesta que el legislador comunitario hace por la forma escrita en este proceso, dicha decisión deberá adoptarse en su caso con suma prudencia. Pues, como subraya el Considerando 9 del Reglamento, el tribunal ha de respetar «el derecho a un juicio justo $y$ el principio contradictorio del proceso» en todo momento, pero "especialmente cuando se pronuncie sobre la necesidad de una vista oral, sobre los medios de práctica de la prueba y sobre el alcance de

${ }^{11}$ A. VAlEnCia Mirón, «El proceso europeo de escasa cuantía», ob. cit., pág. 264. 
la práctica de la prueba». Lo que implica una clara limitación al poder de dirección que se reconoce al órgano jurisdiccional en este punto, que, sea cual sea la decisión que adopte, deberá hacerlo de forma motivada, sin que sean admisibles respuestas escuetas o estandarizadas que impidan conocer los verdaderos motivos por los que se adopta ${ }^{12}$.

Esta opción por la escritura, unida al hecho de que el proceso de escasa cuantía está pensado para que las partes puedan actuar por sí mismas, sin necesidad de estar representadas por abogado u otro profesional del derecho, se hace posible articulando un proceso que, en gran medida, se desarrolla a través de formularios ${ }^{13}$, disposición bienintencionada que, sin embargo, como posteriormente veremos, presenta algunos inconvenientes.

16. $\mathrm{Y}$, en segundo término, la de que su desarrollo viene condicionado por cuatro características, relativas al idioma en que ha de desarrollarse el proceso, a la intervención facultativa de profesionales del derecho, a los términos y plazos que han de observarse durante su tramitación y al modo en que han de hacerse las notificaciones.

17. Por lo que hace a la primera de ellas ha de apuntarse que el proceso europeo de escasa cuantía ha de desarrollarse en la lengua oficial del Estado en que se inicie, o, si hay varias, en cualquiera de ellas, lo que no obsta a que, cuando se solicite la ejecución de una sentencia, pueda presentarse el certificado a que se refiere el art. 20.2 del Reglamento en otra lengua que el Estado miembro de ejecución haya indicado como aceptable (art. 25 del RPEEC).

Es evidente que la existencia de distintos idiomas en el territorio de la Unión Europea puede constituir un obstáculo para la agilidad del proceso y puede incrementar sus costes si es necesario realizar alguna traducción. Para solventar dichos inconvenientes, el RPEEC contiene dos previsiones.

De un lado, que el órgano jurisdiccional podrá exigir que se traduzcan los documentos que estén redactados en una lengua distinta a la que se emplee en el proceso solo «en la medida en que se necesite para dictar sentencia» (art. 6.2), lo que plantea el interrogante de cómo podrá alcanzar semejante conclusión si desconoce su contenido, aun cuando parece razonable colegir que esta vendrá determinada por lo que haya apuntado la parte que lo haya aportado, a la que, por tanto, cabe exigir que explique sumariamente qué se dice o expresa en él y por qué conviene tenerlo en cuenta, y la incógnita de a quién cabe exigir dicha traducción, pareciendo razonable entender que deberá aportarla aquel que haya presentado el documento.

De otro, que las partes podrán negarse a admitir un documento si no está redactado en un idioma que entiendan, en «la lengua oficial del Estado miembro requerido, o (en) la lengua oficial o una de las lenguas oficiales del lugar en que deba efectuarse la notificación o al que deba enviarse el documento si existen varias lenguas oficiales en dicho Estado miembro» (art. 6.3), supuesto en el cual el órgano jurisdiccional informará de ello a la parte contraria para que facilite una traducción del mismo.

En el caso de España, el proceso debe desarrollarse íntegramente en castellano, esto es: en la lengua oficial del Estado - que todos los españoles tenemos el deber de conocer y el derecho a usar (art. 3.1 de la Constitución española)-, por más que existan otras cuatro lenguas cooficiales en diferentes territorios del mismo. Así lo corrobora el hecho de que los cuatro formularios previstos por este proceso solo estén disponibles, por lo que hace a nuestro país, en lengua española ${ }^{14}$.

\footnotetext{
${ }^{12}$ Véase a este respecto la STEDH, Sección 2a , de 8 de noviembre de 2016 (TEDH 2016/100), caso Pönkä contra Estonia, en la que se dispone que, habiéndose solicitado la celebración de una vista en un proceso europeo de escasa cuantía, si esta se rechaza, el tribunal tiene la obligación de proporcionar razones por escrito para dicha negativa. El tribunal de Estrasburgo rechazó la alegación de que el demandante no había formulado objeción a dicha decisión, como establece el derecho interno estonio, cuya utilidad no llega a comprender, ya que anteriormente había solicitado expresamente la celebración de una audiencia oral para poder dar su testimonio y el de dos testigos, proporcionando sus razones para dicha petición. Con fundamento en lo anterior, por cinco votos a dos, declaró que, en el caso examinado, había habido violación del artículo 6.1 del Convenio de Roma. La resolución puede consultarse en: http://hudoc.echr.coe.int/spa?i=001-168375

${ }^{13}$ Sobre el uso de formularios estandarizados, véase G. García-Rostán Calvín, «Los formularios y el proceso de legalidad», en Aciertos, excesos y carencias en la tramitación del proceso (obra dirigida por Juan Francisco Herrero Perezagua y Javier López Sánchez), Ed. Atelier, Barcelona, 2020, págs. 87-102.

${ }^{14} \mathrm{Cfr}$. https://e-justice.europa.eu/content_small_claims_forms-177-es.do
} 
Ello no implica, sin embargo, que no puedan presentarse documentos redactados en euskera, catalán, gallego o valenciano. En absoluto. Pueden presentarse. Pero conviene tener en cuenta, como antes se apuntó, que, si se presenta algún documento redactado en alguno de dichos idiomas, el tribunal podrá exigir su traducción y la parte contraria negarse a admitirlos, hipótesis en la que el órgano jurisdiccional solicitará su transcripción a quien los haya aportado.

18. En relación con la segunda debe apuntarse que las partes pueden actuar en él por sí mismas, ya que no se les exige estar representadas por abogado ni por cualquier otro profesional del derecho (art. 10 del RPEEC). Lo que explica la posición activa que se reconoce al letrado de la Administración de Justicia en diferentes momentos del proceso, cuando este se desarrolla en nuestro país, aspecto que posteriormente desarrollaremos, y la necesidad de que el tribunal informe a las partes del significado y contenido de las cuestiones procesales que deban ser atendidas a lo largo del pleito (art. 12.2 del RPEEC).

Esta circunstancia se proclama en el Reglamento de forma objetiva, y por tanto sin conexión alguna con lo que dispongan los ordenamientos nacionales de los países en que resulta aplicable, para aquellos supuestos en los que el valor económico del litigio no sea superior a 5.000€. Lo que da lugar a una situación ciertamente singular en nuestro país, en el que, como es sabido, los litigantes pueden comparecer por sí mismos cuando el proceso se tramita por razón de la cuantía y esta no excede de $2.000 €$, pero no en los restantes casos, en los que deben hacerlo defendidos por letrado y representados por procurador (cfr. los arts. 23 y 31 de la LECiv). Bien entendido, ello supone que, así como en los procesos que se sigan en nuestro país con arreglo a nuestro derecho interno, es preciso contratar los servicios de dichos profesionales cuando el valor económico de los mismos sobrepasa los $2.000 €$, en los que sigan en nuestro territorio conforme a los cauces del proceso europeo de escasa cuantía solo es preciso hacerlo si dicho valor económico excede de 5.000€. Y, por tanto, que se establece un distinto régimen de postulación procesal en función de que el asunto sea o no transfronterizo y se siga un proceso regulado en nuestro derecho nacional o el previsto en el RPEEC.

Ello suscita, qué duda cabe, el interrogante de si los legisladores nacionales deberían revisar el criterio establecido en la Ley de Enjuiciamiento Civil, incrementando los límites económicos a partir de los cuales resulta necesario contratar los servicios de abogado y procurador, cuestión ciertamente compleja, habida cuenta los intereses en juego y el hecho cierto de que la mayor o menor dificultad de los litigios no viene determinada por la cuantía económica de estos, sino por la cuestión que se debate ante la jurisdicción ${ }^{15}$.

Dicho esto, conviene subrayar de inmediato que el hecho de que, en algunos casos, las partes no precisen actuar representadas por procurador y defendidas por letrado no significa que no puedan contratar sus servicios. En modo alguno. Al contrario, en muchos supuestos será conveniente que lo hagan, habida cuenta la complejidad que puede revestir el asunto, el desconocimiento de los términos y trámites jurídicos y la dificultad que entraña la técnica litigiosa.

Cuestión distinta, pero íntimamente relacionada con la anterior, es la de si el litigante que contrate los servicios de dichos profesionales cuando se siga un proceso europeo de escasa cuantía en aquellos casos en que no resulta preceptiva su intervención, puede incluir los honorarios de estos -o parte de los mismos- en las costas que ha de satisfacer la contraparte en aquellos casos en que gane el pleito. De acuerdo con lo dispuesto en el art. 16 del RPEEC, puede hacerlo si su importe es proporcional al valor de la demanda o fue necesario realizarlos ${ }^{16}$, lo que genera la duda de cuándo puede entenderse que son

Con anterioridad, así se indicaba en el documento titulado «Información comunicada por los Estados miembros de conformidad con al artículo 25 del Reglamento (CE) no 861/2007 del Parlamento Europeo y del Consejo, de 11 de julio de 2007, por el que se establece un proceso europeo de escasa cuantía» que se encontraba disponible en: http://ec.europa.eu/justice_home/judicialatlascivil/html/pdf/vers_consolidade_es_861.pdf.

${ }^{15}$ Con todo, repárese en que ello ya se prevé en otras leyes. Por ejemplo, en la Ley de Jurisdicción Voluntaria, cuyo artículo 62.4, a propósito de la autorización o aprobación judicial para la realización de actos de disposición, gravamen u otros que se refieran a los bienes y derechos de menores y personas con capacidad modificada judicialmente, dispone: «No será preceptiva la intervención de Abogado ni Procurador siempre que el valor del acto para el que se inste el expediente no supere los 6.000 euros, siendo necesaria su actuación en otro caso».

${ }^{16}$ Artículo 16 del RPEEC: «La parte perdedora soportará las costas del proceso. No obstante, el órgano jurisdiccional no 
adecuados al valor del litigio o fue necesario realizar dicho gasto, cuestiones que no esclarece y pueden ser fuente de no pocos problemas, habida cuenta la posibilidad de que existan criterios dispares en este punto cuando se proceda a tasar las costas.

Restan por analizar tres cuestiones relevantes en aquellos casos en que se siga en España un proceso europeo de escasa cuantía.

En primer término, si quienes se enfrenten en él pueden solicitar que se les reconozca el derecho a litigar gratuitamente y, en caso afirmativo, si tienen derecho a que se les designe defensa y representación gratuitas por abogado y procurador. Si nos atenemos a lo que dispone nuestra Ley de asistencia jurídica gratuita, parece claro que, quienes cumplan los requisitos objetivos y subjetivos señalados en dicha norma (vide sus arts. 2 a 5), tienen derecho a que se les concedan las prestaciones inherentes al derecho de asistencia jurídica gratuita y, por tanto, a que se les designe abogado y procurador, aunque su intervención no sea preceptiva, cuando esta «sea expresamente requerida por el juzgado o tribunal mediante auto motivado para garantizar la igualdad de las partes en el proceso» (art. 6.3). Lo que permite concluir que, si bien como regla general el reconocimiento del derecho de asistencia jurídica gratuita no comprende la defensa y representación gratuitas cuando la intervención de abogado y procurador no es preceptiva, como excepción, cuando el tribunal expresamente la requiera para garantizar la igualdad de las partes, sí lo hará. La posibilidad, por tanto, existe. Aun cuando a tenor de lo dicho será sumamente difícil que llegue a concretarse, a no ser -claro está- que se entienda que aquella es necesaria siempre que la contraparte comparezca defendida, y en su caso representada, por profesionales jurídicos.

En segundo lugar, si resulta necesario contratar los servicios de abogado y procurador para recurrir la sentencia de primera instancia, en aquellos casos en que sea posible impugnarla. El RPEEC no contiene ninguna previsión al respecto. Por lo que, de acuerdo con lo que apuntamos anteriormente, ha de estarse a lo que disponga cada legislación nacional. En el caso concreto de España, al requerirse la intervención de dichos profesionales siempre y en todo caso en segunda instancia (vid. los artículos 23, 31 y 455.1 de la LECiv), parece claro que será necesario hacerlo para recurrir en apelación la que se haya dictado en primer grado.

Y, finalmente, si se precisa abogado y procurador en el proceso de ejecución, cuestión sobre la que tampoco se dice nada en el Reglamento y en la que, por tanto, se ha de estar a lo que disponga cada legislación nacional, señalándose en la nuestra que tanto el ejecutante como el ejecutado deben actuar dirigidos por letrado y representados por procurador, «salvo que se trate de la ejecución de resoluciones dictadas en procesos en que no sea preceptiva la intervención de dichos profesionales» (art. 539.1 de la LECiv), hipótesis en las que no es necesario contratar sus servicios. De donde se deduce que, no siendo precisa la intervención de los mismos en el proceso europeo de escasa cuantía cuando el valor económico del pleito no exceda de 5.000€, tampoco lo es para la ejecución de la sentencia que en estos casos le haya puesto fin.

19. Por lo que hace a la tercera debe significarse que las actuaciones procesales deben realizarse en los plazos y términos que señala el RPEEC, el cual, si bien regula con carácter general el lapso de tiempo en que ha de tener lugar una determinada actividad ${ }^{17}$, en algunos casos permite que sean los órganos jurisdiccionales los que lo fijen (cfr. el art. 4.4 del RPEEC), autorizándoles asimismo a que puedan prorrogar determinados plazos cuando concurran circunstancias excepcionales que así lo aconsejen, a fin de garantizar los derechos de las partes (vide lo dispuesto al respecto en el art. 14 del RPEEC).

Se trata, sin duda, de una posibilidad que, en su caso, deberá utilizarse con prudencia y mesura, a fin de no violentar la necesaria imparcialidad de los órganos jurisdiccionales, materia en la cual «hasta las apariencias importan», lo que ha permitido concluir al Tribunal de Estrasburgo que «para decidir

condenará a la parte perdedora a pagar a la parte ganadora costas generadas innecesariamente o que no guarden proporción con el valor de la demanda» (el subrayado es nuestro).

${ }^{17}$ De acuerdo con lo previsto en su Considerando 24, a efectos del cálculo de los plazos dispuesto en dicho Reglamento ha de estarse a lo previsto en el Reglamento 1182/71 del Consejo, de 3 de junio de 1971, por el que se determinan las normas aplicables a los plazos, fechas y términos, aclarando la disposición final vigésima cuarta de nuestra LECiv, en su apartado 1, que en dicho cómputo no se excluyen los días inhábiles, lo que tiene especial transcendencia, habida cuenta la excepción que supone en relación con la regla general que impera en nuestro país en este punto. 
sobre la existencia, en un caso concreto, de una razón legítima para temer de un tribunal una falta de imparcialidad, se ha de tener en cuenta el punto de vista del interesado aunque no juega un papel decisivo. El elemento determinante consiste en saber si sus aprensiones pueden considerarse objetivamente justificadas (Sentencias Ferrantelli y Santangelo contra Italia, ap. 58, 7 agosto 1996, Repertorio 1996-III y Wettstein contra Suiza, núm. 33958/1996, ap. 44, TEDH 2000-XII)»» .

20. Por último, en relación con el modo en que han de hacerse las notificaciones en este proceso, es evidente que estas han de practicarse de forma que no se produzcan demoras ni retrasos, razón por la cual el art. 13.1 del RPEEC establece que, como regla general, los documentos se notificarán por correo con acuse de recibo donde conste la fecha de recepción y que, cuando no sea posible hacerlo así, la notificación podrá realizarse por cualquiera de los procedimientos establecidos en los artículos 13 o 14 del Reglamento (CE) núm. 805/2004, por el que se establece un título ejecutivo europeo para créditos no impugnados, que contemplan sistemas de comunicación que no exigen la entrega personal al destinatario.

\section{IV.Procedimiento}

21. Como antes se apuntó, el proceso europeo de escasa cuantía se inicia y tramita en la forma prevista en el Reglamento (CE) núm. 861/2007, norma que ha optado por un sistema de formularios estandarizados ${ }^{19}$ con el doble propósito de facilitar su tramitación ${ }^{20}$, especialmente si quien opta por este proceso no está asistido por abogado ${ }^{21}$, y de mitigar en lo posible las dificultades derivadas de la existencia de diversos idiomas en la Unión Europea y la confusión e indudable indefensión que una mala traducción de los términos jurídicos podría causar a los litigantes.

\section{A) Demanda}

22. El proceso principia por demanda. $\mathrm{Y}$, aunque el RPEEC prevé el uso de unos formularios estandarizados con el propósito de favorecer el acceso a la justicia, ha de entenderse que ello es solo una posibilidad que se ofrece al actor, no una exigencia. Por lo que este podrá optar por hacer uso de los mismos o por presentar una demanda conforme a los cánones usuales, en la que deberán referirse, eso sí, cuando menos, todos los extremos que se refieren en el formulario estándar de demanda que se incluye como anexo I en el Reglamento.

Es cierto que ello no se prevé en el Reglamento, que en todo momento se refiere a la utilización de formularios, y que tal circunstancia puede ofrecer dudas sobre lo que acaba de apuntarse. Sin embargo, el que el demandado pueda responder a la demanda sin hacer uso del formulario de contestación (art. 5.3 del mismo, in fine) justifica que el actor pueda formular su pretensión sin hacer uso necesariamente del formulario estándar de demanda por razones evidentes de igualdad. Lo importante no es, por tanto, que las alegaciones consten o no en un impreso con espacios en blanco que se ofrece a las partes, sino

${ }^{18}$ STEDH de 6 de enero de 2010 (TEDH 2010/3), asunto Vera Fernández-Huidobro contra España. También resulta interesante a este respecto la STEDH de 6 de noviembre de 2018, en el caso Otegi Mondragón y otros contra España.

${ }^{19}$ A tal fin, pone a disposición de los particulares un listado de cuestiones que han de abordar si desean que su petición sea admisible, acompañado de algunas observaciones explicativas de cada una de ellas.

${ }^{20} \mathrm{El}$ legislador suele equiparar procesos de escasa cuantía con asuntos sencillos y poco complejos, correspondencia inexacta, y por tanto incorrecta, ya que la realidad pone de manifiesto que existen asuntos de reducida entidad económica que encierran cuestiones fácticas y/o jurídicas especialmente complejas y complicadas. De ahí que dicha identificación implique un gran desconocimiento del quehacer diario en nuestros tribunales y de lo que es el derecho.

${ }^{21}$ En efecto, el proceso europeo de escasa cuantía está concebido como un proceso sin abogados, lo que supone una opción por una «justicia de ciudadanos», sin intermediarios, en feliz expresión de F. GASCón InCHAUSTI, «Un nuevo instrumento para la tutela de los consumidores y de los créditos transfronterizos: El proceso europeo de escasa cuantía», en Ius et Praxis, año 14, núm. 1, págs. 167-197. 
que estas hagan constar en sus escritos determinados datos que se consideran necesarios e imprescindibles. Cumplido este requisito, que lo hagan o no en esos impresos resulta intrascendente.

23. En la demanda, se haga uso o no del «formulario estándar de demanda A, tal como figura en el anexo $I\rangle^{22}$, que ha de incluir una descripción de los elementos probatorios en que se fundamenta e ir acompañada «cuando proceda, de todo documento justificativo pertinente» (art. 4.1 del RPEEC), deben referirse los siguientes extremos:

a) El tribunal ante el que se presenta ${ }^{23}$, señalando a tal fin su denominación y localización postal (calle y número o apartado de correos; ciudad y código postal; y país).

b) Los datos que permitan identificar y localizar a las partes (necesariamente: nombre y apellidos o razón o denominación social; calle y número o apartado de correos donde puede localizárseles; ciudad y código postal; y país. Con carácter facultativo, y por tanto no preceptivo: número de teléfono; dirección de correo electrónico; identificación, en su caso, del representante del actor y/o del demandado, e información de contacto; y otros datos útiles para su reconocimiento, como, por ejemplo, y sin ánimo de exhaustividad, su fecha y lugar de nacimiento; empleo, profesión o cargo; y número de documento nacional de identidad o de identificación fiscal).

c) Las reglas conforme a las que se ha determinado la competencia.

El Reglamento no contiene disposición alguna referida a la competencia de los órganos jurisdiccionales, limitándose a señalar que, como muy tarde, el 1 de enero de 2008 los Estados miembros de la Unión que lo suscribieron (esto es, todos, menos Dinamarca) debían informar a la Comisión sobre los órganos competentes para dictar resoluciones en el proceso de escasa cuantía, así como, entre otros extremos, sobre si su derecho procesal contemplaba la posibilidad de recurrir la decisión que le pusiera fin (vid. su art. 24).

Posteriormente, España aprobó la Ley 4/2011, de 24 de marzo, de modificación de la Ley 1/2000, de 7 de enero, para facilitar la aplicación en España de los procesos europeos monitorio y de escasa cuantía, por la que se añadió una nueva disposición final a la LECiv, la vigésima cuarta, titulada «Medidas para facilitar la aplicación en España del Reglamento (CE) n. ${ }^{\circ} 861 / 2007$ del Parlamento Europeo y del Consejo, de 11 de julio de 2007, por el que se establece un proceso europeo de escasa cuantía», en la que se da respuesta a dicho interrogante, al señalar que la competencia objetiva corresponde a los juzgados de primera instancia o de lo mercantil, en función de cuál sea el objeto de la reclamación ${ }^{24}$, y que la competencia territorial se determinará conforme a lo dispuesto en el Reglamento (CE) 44/2001 del Consejo, de 22 de diciembre de 2000, relativo a la competencia judicial, el reconocimiento y la ejecución de resoluciones judiciales en materia civil y mercantil ${ }^{25}$, y, en lo no previsto, con arreglo a la legislación procesal española, es decir, de acuerdo con las reglas previstas en los arts. 50 y siguientes de la LECiv.

\footnotetext{
${ }^{22}$ Deben existir formularios de demanda en todos los órganos jurisdiccionales ante los que pueda incoarse este proceso (art. 4.5 del RPEEC).

${ }^{23}$ La determinación de cuál es el órgano jurisdiccional competente no es asunto fácil ni siquiera para quien está versado en derecho, por lo que menos aún lo es para el neófito o lego en esta ciencia. De ahí que el formulario de demanda que se pone a disposición de quien desee hacer uso del mismo ofrezca un listado -no exhaustivo- de posibles criterios que, de acuerdo con el Reglamento núm. 44/2001, permiten fundar la llamada competencia internacional (domicilio del demandado; domicilio del consumidor; domicilio del titular de la póliza, el asegurado o el beneficiario en asuntos de seguros; lugar de cumplimiento de la obligación reclamada; lugar del daño; elección del tribunal acordada de común consenso por las partes), remitiendo al sitio Internet del Atlas Judicial Europeo para más información sobre las normas de atribución de competencia y a otra página de Internet para una mejor comprensión de los términos jurídicos utilizados.

${ }^{24}$ Dicha información también consta en https://e-justice.europa.eu/content_small_claims-354-es-es.do?member=1\#a_111

${ }^{25}$ Con posterioridad se aprobó el Reglamento (UE) núm. 1215/2012, del Parlamento Europeo y del Consejo, de 12 de diciembre de 2012, relativo a la competencia judicial, el reconocimiento y la ejecución de resoluciones judiciales en materia civil y mercantil, que, con carácter general, entró en vigor el 10 de enero de 2015.
} 
Con el propósito de favorecer el conocimiento de lo anterior a quienes carezcan de los necesarios conocimientos jurídicos y no deseen contratar los servicios de un abogado o experto en leyes, se facilita información sobre el proceso europeo de escasa cuantía y los tribunales ante los que puede presentarse la demanda en https://e-justice.europa.eu/content_small_ claims-354-es-es.do?member=1\#a_111.

d) La justificación de que se trata de un asunto transfronterizo, requisito esencial para que pueda seguirse este proceso, entendiéndose que lo es -tal y como apuntamos líneas atrás- todo aquel en el que, al menos una de las partes, está domiciliada o reside habitualmente en un Estado miembro distinto de aquel al que pertenezca el órgano jurisdiccional que conozca del pleito.

e) Información del modo en que se piensa abonar la tasa judicial, en aquellos países en los que se requiera, admitiéndose su pago mediante tarjeta de crédito, cobro directo en una cuenta corriente del actor, transferencia bancaria u otro medio que éste especifique, siendo preciso que, en los dos primeros casos, se consignen los datos de la tarjeta de crédito o de la cuenta corriente en un apéndice del formulario que, a fin de preservar dicha información, está destinado exclusivamente al órgano jurisdiccional y no se transmitirá al demandado.

En España, según la información proporcionada por el Gobierno a la Comisión Europea ${ }^{26}$, el proceso europeo de escasa cuantía no se encuentra incluido entre los procesos sujetos a tasa judicial.

f) El objeto sobre el que versa el litigio. A tal fin, resulta preciso especificar si se reclama o no una suma dineraria: en el primer caso, la moneda en que se desea el pago de lo solicitado; en el segundo, el valor estimado de la demanda, especificando la moneda en la que se cuantifica, y si se presenta «una demanda secundaria de indemnización para el caso de que no pueda darse curso favorable a la demanda original»; si se pide la condena en costas de la contraparte y, en caso afirmativo, qué costas se exigen y la cantidad requerida o gastada hasta la fecha; y si se reclaman o no intereses, significando en caso afirmativo si se trata de intereses legales o contractuales y, en ambos casos, la fecha a partir de la cual, a juicio del reclamante, deben computarse.

g) Los motivos por los que se demanda, especificando por ejemplo lo que ocurrió y el lugar y fecha en que sucedió, y los medios de prueba que se proponen para acreditar lo que se reclama, indicando los puntos de aquella a que vienen referidos, pudiendo solicitarse en este momento que se celebre una vista oral con presencia de todas las partes para centrar los términos de la controversia que las enfrenta, supuesto en el cual pueden especificarse las razones que, a juicio del actor, la hacen aconsejable o conveniente.

h) Si se interesa que el tribunal que conozca del asunto expida un certificado de la sentencia que se dicte al objeto de que pueda ejecutarse en otro Estado miembro de la Unión al que afecte lo dispuesto en el Reglamento.

i) La solicitud de que se dicte sentencia de conformidad con lo expuesto; la declaración de que la información facilitada es correcta por lo que le consta al actor y se presenta de buena fe; el lugar donde se ha redactado la demanda (lo cual es intrascendente, porque lo significativo es dónde se presenta), la fecha en que se ha concluido (aun cuando la misma es irrelevante, toda vez que la que realmente importa es la del día en que se presenta); y el nombre, apellidos y firma de quien la suscribe.

24. Dicho escrito, que ha de estar redactado en alguna de las lenguas a que antes se hizo referencia, debe presentarse «directamente ante el órgano jurisdiccional competente o enviándolo por correo postal o por cualquier otro medio de comunicación (fax, correo electrónico, etc.) admitido por el Estado miembro en el que se inicie el proceso» (art. 4.1 del RPEEC) ${ }^{27}$.

\footnotetext{
${ }^{26}$ Vide https://e-justice.europa.eu/content_small_claims-354-es-es.do?member=1\#a_111

${ }^{27}$ Para que este último dato -el de aquellos otros medios de comunicación a través de los cuales es posible presentar la demanda- sea conocido por todos, el art. 4.1 del RPEEC obliga a los Estados afectados por dicha norma a informar a la Comisión de cuáles son los que considera admisibles, a fin de que ésta lo haga público para general conocimiento de los interesados.
} 


\section{B) Examen de la demanda y, en su caso, admisión a trámite}

25. Presentada la demanda, debe examinarse si el tribunal al que se ha dirigido tiene jurisdicción y competencia para conocer; si su objeto está incluido en el ámbito de aplicación del Reglamento; si resulta fundada y admisible; y, por último, si la información proporcionada por el actor es suficiente y el formulario, en su caso, está bien cumplimentado.

26. En nuestro país, el primer examen para determinar si una demanda es o no admisible lo llevan a cabo los letrados de la Administración de Justicia.

Por tal razón, son ellos los encargados de verificar inicialmente si se cumplen los referidos presupuestos.

Si el letrado de la Administración de Justicia competente para ello considera que dichos presupuestos han sido debidamente observados, admitirá a trámite la demanda mediante decreto (vide la disposición final vigésima cuarta de la LECiv, apartado 3).

Si por el contrario considera que no es así, adoptará diferentes decisiones, en función del vicio que entienda que se ha producido.

1. Si considera que la demanda se ha presentado ante un tribunal carente de jurisdicción y/o competencia, dará cuenta a este de dicha circunstancia para que, tras el pertinente examen, se pronuncie sobre esta cuestión.

2 Si entiende que el objeto sobre el que versa la demanda no está incluido en el ámbito de aplicación del Reglamento, informará al actor de su parecer para que, si lo tiene a bien, desista de ella en el plazo que le conceda al efecto, acordando en caso contrario que se tramite por los cauces del proceso declarativo que corresponda ${ }^{28}$.

Si se piensa con detenimiento, y, por tanto, con método y orden, enseguida se cae en la cuenta de que esta última decisión no debería ser adoptada por los letrados de la Administración de Justicia sino por los tribunales a los que, en cada caso, se haya dirigido la demanda.

De un lado, porque es tan relevante que no parece razonable que sea adoptada por persona distinta a quien está llamada a pronunciarse sobre lo pretendido por el actor, por más que los letrados de la Administración de Justicia sean quienes ostentan la jefatura de la oficina judicial (art. 440 de la LOPJ).

De otro, porque, iniciada ya la causa, es el tribunal el que debe decidir sobre esta cuestión cuando es el demandado el que alega la inadecuación de procedimiento (cfr. el art. $416.1 \mathrm{de}$ la LECiv). Por lo que parece razonable que también sea él quien lo haga en este momento.

Ello no implica ninguna descortesía hacia los letrados de la Administración de Justicia, que integran un cuerpo de funcionarios altamente cualificados que merecen todo nuestro reconocimiento y respeto. En absoluto. Supone destacar que la tarea de juzgar y hacer cumplir lo juzgado se desarrolla a lo largo de todo el proceso, no solo en la sentencia, y que, siendo así, todo enjuiciamiento con transcendencia procesal para las partes debe realizarse por quienes tienen atribuida la potestad y función jurisdiccional, no por otros.

3. Si, estima que la demanda carece manifiestamente de fundamento o es inadmisible, dará traslado de la misma al tribunal para que este adopte la decisión que considere más acorde a derecho. Si el tribunal confirma su criterio, de conformidad con lo indicado en el artículo 4.4,

A este respecto, España ha indicado que «Además de la presentación directa ante el Juzgado competente, y la presentación a través de correo postal los tribunales españoles también admiten la presentación de las demandas a través de las sedes judiciales electrónicas de las Administraciones competentes en materia de Administración de Justicia» (cfr. https://e-justice.europa.eu/ content_small_claims-354-es-es.do?member=1\#a_111).

${ }^{28}$ Pese a ello, en el caso analizado en el Auto del Juzgado de lo Mercantil núm. 1 de Valencia de 3 de marzo de 2020 (ECLI: ES:JMV:2020:20A), Pte. Sr. Vilata Menadas, se acuerda inadmitir la demanda por no ser el asunto transfronterizo (según indicó el actor en su demanda, tanto este como la compañía aérea demandada tienen su domicilio en España) y, en consecuencia, no poder tramitarse la causa por los trámites del proceso europeo de escasa cuantía. 
II del Reglamento ${ }^{29}$, la desestimará, decisión que, en su caso, adoptará mediante auto, que, al ser definitivo, podrá ser recurrido en apelación (art. 455.1 de la LECiv).

El Reglamento plantea aquí una cuestión de difícil encaje en nuestro ordenamiento.

De un lado, porque resulta difícil imaginar supuestos en los que desde el inicio sea posible advertir que la demanda carece claramente de fundamento, conclusión que conlleva un enjuiciamiento sobre el fondo de la cuestión que, en nuestro sistema de justicia, de ordinario, no puede hacerse in limite litis.

De otro, porque, en su caso, de aceptarse que dicho enjuiciamiento puede realizarse tras la lectura de la demanda, la conclusión más lógica, sensata y ponderada, desde cualquier punto de vista, también el jurídico, sería inadmitirle a trámite, a fin de que el infractor pudiera en su caso subsanar la falta cometida, no desestimarla, lo que implica una decisión de fondo que inhabilita -como es sabido- para suscitar de nuevo la cuestión ante la jurisdicción ${ }^{30}$. La versión francesa del documento -recuérdese que los dos idiomas oficiales de la Unión Europea son el francés y el inglés-, al indicar que, en este supuesto, «la demande est rejetée» (art. 4.4 del Reglamento), expresión que puede ser traducida en el sentido de que no será admitida, confirma nuestra conclusión.

En relación con lo anterior también debe tenerse en cuenta que el Considerando 13 del Reglamento dispone que los conceptos «manifiestamente infundada»e «inadmisible» deben determinarse de acuerdo con la legislación nacional del Estado de que se trate, lo que implica tener en cuenta tanto su normativa sustantiva como procesal y que nuestra regulación procesal civil sólo niega que exista accionabilidad, esto es: posibilidad de reclamar con éxito la tutela jurisdiccional que se solicita, en supuestos muy excepcionales como el previsto en el artículo 42 del Código Civil, por lo que la regla general es exactamente la contraria.

4. Si valora que la información proporcionada por el actor no es pertinente, suficientemente clara o que, en su caso, la demanda no ha sido debidamente cumplimentada, utilizando el formulario estándar B que figura en el anexo II del Reglamento, solicitará al actor que la complete o rectifique, que le facilite la información que considere necesaria o, en su caso, que la retire. Si subsana los yerros detectados, admitirá a trámite la demanda. Si no lo hace, dará traslado al tribunal para que este decida si procede desestimar la demanda.

La posibilidad de que se pueda solicitar información adicional a la proporcionada inicialmente se explica por el deseo del legislador europeo de facilitar el acceso a la justicia a los ciudadanos de la Unión sin necesidad de que contraten los servicios de letrados u otros profesionales jurídicos. Si la intervención de estos no es preceptiva, la única forma de suplir los errores que puedan cometer los legos en derecho es que una autoridad estatal supervise su reclamo y le señale, en su caso, en qué punto debe ser completado. En consecuencia, desde este punto de vista, no hay nada que objetar.

Sin duda, dicha eventualidad suscita dudas desde la perspectiva de los principios que rigen los procesos en el orden civil, en los que son las partes a las que corresponde alegar los hechos y proponer los medios de prueba con los que pretenden acreditar las afirmaciones que hayan realizado sobre aquellos, sin ayuda o colaboración del órgano llamado a resolver sus pretensiones. Pero, siendo ello verdad, no puede dejar de tenerse en cuenta que el proceso

\footnotetext{
${ }^{29}$ Véase la versión que se refiere en https://eur-lex.europa.eu/legal-content/ES/TXT/PDF/?uri=CELEX:32007R0861\&fro $\mathrm{m}=\mathrm{ES}$.

${ }^{30}$ En igual sentido: Auto del Juzgado de lo Mercantil núm. 10 de Barcelona de 15 de diciembre de 2020 (ECLI: ES:JMB:2020:149A), Pte. Sra. Martínez Orejas. En el supuesto analizado en dicha resolución, el letrado de la Administración de Justicia «observó el defecto formal consistente en presentar la demanda de forma telemática e indicar y acreditar la competencia territorial de este juzgado y, conforme al principio de subsanación de los defectos en que incurran los actos procesales de las partes recogido en el art. 231 de la Ley de Enjuiciamiento Civil (LEC), concedió a la parte demandante el plazo de CINCO días para que lo subsanara; bajo apercibimiento, en caso de no verificarlo, de poder acordar el archivo de las actuaciones», sin que esta lo hiciese, razón por la cual se dio traslado a la titular de dicho Juzgado, que acordó inadmitir a trámite la demanda, anunciando en su resolución que contra la misma podía interponerse recurso de apelación ante la Audiencia Provincial de Barcelona, conforme a lo previsto en el art. 455 de la LECiv.
} 
europeo de escasa cuantía nació con el propósito confeso de facilitar el acceso a la justicia y fijar normas comunes en todos los países de la Unión Europea para acreedores y deudores y que dicho fin se consideró aceptable por nuestro país al rubricar su regulación, por más que existan cuestiones que puedan resultar discutibles.

Por lo demás, cabe reproducir aquí la crítica antes referida en relación con la consecuencia que se anuda a que no se cumplan los requerimientos efectuados por el letrado de la Administración de Justicia: la desestimación de la demanda sería injusta y desproporcionada y no se compadece con la pretendida por el legislador europeo, tal y como se ha expuesto anteriormente.

\section{C) Traslado de la demanda al demandado}

27. Admitida a trámite la demanda, y dentro de los catorce días siguientes a aquel en que se haya recepcionado, el letrado de la de Administración de Justicia debe enviar al demandado una copia de la misma, de los documentos que, en su caso, se hayan adjuntado a ella y del formulario de contestación, en el que habrá debido cumplimentar «la parte I del formulario estándar de contestación C, tal como figura en el anexo III» (art. 5.2 del RPEEC).

\section{D) Posibles conductas del demandado frente a la demanda}

28. Una vez que el demandado tiene oficialmente constancia de que se ha interpuesto frente a él una demanda que se tramita por los cauces del proceso europeo de escasa cuantía dispone de treinta días para contestarla.

En realidad, tiene diversas opciones.

En primer lugar, puede no comparecer en las actuaciones.

En segundo término, puede comparecer en ellas y no contestar a la demanda, supuesto posible aunque poco frecuente en la práctica ${ }^{31}$.

Finalmente, puede comparecer en el proceso y contestar a la demanda, hipótesis en la cual puede allanarse a ella, total o parcialmente, oponerse a la misma - «bien cumplimentando la parte II del formulario estándar de contestación C, acompañada, en su caso, de los documentos justificativos pertinentes, y devolviéndola al órgano jurisdiccional, o bien por cualquier otro medio adecuado, sin hacer uso del formulario de contestación» (art. 5.3 del RPEEC)- e incluso formular reconvención «mediante el formulario estándar A y los documentos justificativos pertinentes» (art. 5.5 del RPEEC). Todo ello, como se ha dicho, dentro de los treinta días siguientes a aquel en que se le hayan notificado los formularios de demanda y de contestación a la misma.

29. Si decide contestar a la demanda, en su escrito debe pronunciarse sobre distintos extremos.

En primer lugar, ha de manifestar si se allana o no a la demanda y, en su caso, si lo hace total o parcialmente, indicando, si no lo hiciera, los motivos por los que no accede a lo requerido por el actor, señalándose en el formulario de contestación que dicha negativa puede obedecer a que «la demanda queda fuera del ámbito de aplicación del proceso de escasa cuantía» o a otras razones, que, de existir, deben señalarse.

En segundo término, si se opone a lo solicitado por el actor, debe referir los medios probatorios que desea presentar a su favor, señalando a qué puntos de sus alegaciones se refieren, añadiendo, cuando sea conveniente, los documentos justificativos correspondientes.

\footnotetext{
${ }^{31} \mathrm{Al}$ igual que ocurre en el derecho patrio, tanto éste como el anterior supuesto no implican que el tribunal deba dictar necesariamente sentencia favorable al actor; al contrario, dictará la que considere más fundada en derecho en función de las circunstancias que se le refieran, por lo que perfectamente puede desestimar la demanda oportunamente formulada (como también, por las mismas razones, la reconvención no contestada).
} 
A continuación, ha de indicar si solicita o no la celebración de una vista oral y, si lo hace, los motivos por los que la cree necesaria; si pide la condena en costas de la parte contraria y, en caso afirmativo, qué tipo de costas solicita y, si es posible, la cantidad reclamada o gastada hasta la fecha; y finalmente si desea formular reconvención, supuesto en el cual debe cumplimentar y adjuntar «un formulario A por separado».

Por último, podrá añadir las alegaciones que estime necesarias, concluyendo el escrito con la declaración de que la información que ha facilitado es correcta, por lo que le consta, y se presenta de buena fe; la fecha en que se redacta; y la firma de quien lo suscribe.

30. Presentada la contestación del demandado, y dentro de los catorce días a partir de su recepción, el letrado de la Administración de Justicia enviará una copia al actor junto con los documentos justificativos pertinentes (art. 5.4 del RPEEC).

Si el demandado hubiese alegado en su respuesta que el valor de la demanda supera el límite propio del proceso europeo de escasa cuantía, el tribunal decidirá por auto en un plazo de treinta días tras el envío de la contestación al actor, si la demanda entra dentro del ámbito de aplicación del Reglamento o ha de tramitarse por los cauces de alguno de los procesos declarativos ordinarios que prevé la LECiv, sin que contra su decisión quepa interponer recurso alguno en ese momento, sin perjuicio de que pueda reproducirse la alegación al recurrir en apelación la sentencia que llegue a dictarse (art. 5.5 del RPEEC y disposición final vigésima cuarta, apartado 4, de la LECiv) ${ }^{32}$.

31. Si el demandado hubiese formulado reconvención ${ }^{33}$, se notificará esta al actor en un plazo de catorce días a partir de su recepción, quien dispondrá de un plazo de treinta días para contestarla, a contar desde el que se le haya notificado.

Por cuanto la reconvención sólo es admisible en relación con el mismo contrato o hecho que fundamenta la demanda inicial (Considerando 16 del RPEEC), parece exigible una cierta conexión entre ésta y la demanda reconvencional ${ }^{34}$, aun cuando ciertamente no se requiere de modo expreso. Posiblemente porque, a la vista de lo anterior, el legislador comunitario no consideró necesario especificarlo con mayor detalle.

En cualquier caso, lo que sí parece claro es que la demanda reconvencional ha de ser expresa, $\mathrm{y}$, en consecuencia, que no caben reconvenciones implícitas o tácitas, toda vez que debe formularse cumplimentando "un formulario A por separado», lo que evita que puedan vulnerarse derechos tan esenciales como los de defensa, audiencia y contradicción.

Asimismo, por disposición del legislador comunitario, no puede superar el límite cuantitativo referido en el artículo 2.1 del Reglamento. Ya que, si lo hiciere, «la demanda y la reconvención no se tramitarán con arreglo al proceso europeo de escasa cuantía, sino con arreglo a lo que disponga el Derecho procesal aplicable en el Estado miembro en el que se siga el proceso» (vide el art. 5.7 del RPEEC $)^{35}$. Es cierto que ello conlleva el riesgo de que se interponga con el único propósito de evitar

${ }^{32}$ Aunque el Reglamento (CE) núm. 861/2007 nada dice al respecto, parece lógico que, antes de tomar una decisión sobre esta cuestión, el órgano jurisdiccional permita al actor formular las alegaciones que tenga por conveniente con relación a la misma en el plazo que a tal efecto se conceda. En cualquier caso, dicha posibilidad parece obligada si el proceso europeo de escasa cuantía se sigue en España por aplicación de lo dispuesto en la disposición final vigésima cuarta, apartado 4, de la LECiv.

${ }^{33}$ En cuyo caso habrá de cumplimentar un formulario de demanda y acompañarlo de los documentos pertinentes (art. 5.6 del RPEEC).

A la reconvención resulta de aplicación, mutatis mutandis, lo dispuesto en los artículos 2, 4 y 5 -apartados 3,4 y 5- del RPEEC (art. 5.7, II de dicha norma).

${ }^{34}$ Así parece entenderlo también la SAP de Madrid, Sección Octava, de 21 de febrero de 2011 (ECLI: ES:APM:2011:1842), Pte. Sr. García Paredes.

${ }^{35}$ En el caso concreto de España, ante dicha situación, «el juez resolverá mediante auto que el asunto se tramite por el procedimiento que corresponda con arreglo a las normas procesales españolas» (disposición final vigésima cuarta, apartado 4, de la LECiv).

A juicio de Valencia Mirón, el cambio obligado de procedimiento puede generar problemas «porque la tramitación conjunta de la demanda y la reconvención sólo será posible en función del procedimiento aplicable. Si la reconvención excede de los 2.000 euros, pero no supera el umbral de los 6.000 euros, y siempre que la materia objeto del procedimiento lo permita, tanto 
que el proceso se tramite por los cauces del proceso europeo de escasa cuantía ${ }^{36}$. Pero también lo es que dicha finalidad será en su caso muy difícil de acreditar y que, aunque se consiguiese demostrar, ello no impediría la consecuencia que el legislador anuda a dicha circunstancia ${ }^{37}$.

No obstante, es evidente que el cambio obligado de normativa puede generar problemas. En primer lugar, sin duda enlentecerá la resolución de la causa. Y, en segundo término, y por lo que hace a España, puede dar lugar a que sea necesario contratar los servicios de un abogado y un procurador cuando inicialmente no era necesario hacerlo (recuérdese que en el proceso europeo de escasa cuantía la intervención de dichos profesionales no es necesaria y que, en nuestro país, salvo en determinados supuestos, es preceptiva), con el consiguiente coste económico que ello conlleva. Por lo demás, la previsión comunitaria suscita una cuestión que no resuelve: la de qué procede hacer en aquellos supuestos en los que el valor económico de la demanda reconvencional exceda de 6.000€, es decir, del umbral económico previsto por el legislador español para el juicio verbal (art. 250.2 de la LECiv). En semejante caso parece evidente que, puesto que la reconvención no puede tramitarse por los cauces de este, el tribunal deberá declarar inadmisible la reconvención y la continuación de la causa por los trámites del proceso europeo de escasa cuantía ${ }^{38}$.

Para concluir con esta cuestión debe apuntarse que la alegación de un crédito compensable por parte del demandado, que en nuestro derecho constituye una excepción reconvencional y, como tal, tiene un régimen procesal propio (cfr. el art. 408 de la LECiv), no tiene porqué constituir necesariamente una demanda reconvencional en el proceso europeo de escasa cuantía, razón por la cual «el demandado no está obligado a utilizar el formulario estándar A que figura en el anexo I para invocar este derecho» (Considerando 17 del RPEEC), lo que supone que puede ser alegada tanto como excepción como por medio de reconvención ${ }^{39}$.

\section{E) Actuaciones posteriores y dictado de la sentencia}

32. Recibida la respuesta del demandado o, en su caso, la contestación del actor a la reconvención, el tribunal dictará sentencia, si bien, con carácter previo a ello, puede:

- solicitar a las partes información complementaria en relación con la demanda, dentro de un plazo no superior a treinta días;

- ordenar que se proceda a la práctica de la prueba que, habiéndose propuesto debidamente, haya sido admitida ${ }^{40}$;

- o citar a las partes a una vista oral que, en su caso, se celebrará en un plazo de treinta días a partir de la fecha de recepción de la citación y podrá desarrollarse por videoconferencia $\mathrm{u}$ otros sistemas de comunicación en la medida en que se disponga de los medios técnicos correspondientes.

la demanda como la reconvención pueden tramitarse por el juicio verbal, pero si la reconvención excede de 6.000 euros será declarada inadmisible. En este último caso, el Juzgado que conoce del PEC sobre la base del abuso de derecho cometido por el demandado debe declarar inadmisible la reconvención y la continuación del procedimiento conforme al RPEEC» (A. VALENCIA Mirón, «El proceso europeo de escasa cuantía», ob. cit., pág. 315).

${ }^{36} \mathrm{M}^{\mathrm{a}}$. I. GonzÁlez CANo, en El proceso europeo de escasa cuantía, Ed. Tirant lo blanch, Valencia, 2001, pág. 82.

${ }^{37}$ Pardo Iranzo considera que, en estos casos, sería más adecuado tramitar ambas demandas por separado: la demanda principal por los cauces del proceso europeo de escasa cuantía, y la demanda reconvencional por la del proceso declarativo nacional que corresponda (cfr. V. PARDo Iranzo, en La supresión del exequátur: libre circulación de títulos ejecutivos en la Unión Europea, Ed. Tirant lo blanch, Valencia, 2020, pág. 169).

${ }^{38}$ Coincidimos, por tanto, con la tesis referida por A. VALENCIA Mirón, «El proceso europeo de escasa cuantía», ob. cit., pág. 315.

${ }^{39}$ En igual sentido: A. VALENCIA Mirón, «El proceso europeo de escasa cuantía», ob. cit., loc. cit.

${ }^{40}$ A este respecto debe significarse que el órgano jurisdiccional debe utilizar para la práctica de la prueba el método más sencillo y menos oneroso (Considerando 20 del RPEEC); que dicha práctica puede tener lugar por medio de videoconferencia u otros sistemas de comunicación, en la medida en que se disponga de los medios técnicos correspondientes; y que pueden practicarse los medios de prueba que sean admisibles en derecho y, más en concreto, ya que así lo dispone el propio Reglamento en su art. 9, la prueba de expertos o peritos o las de interrogatorio de partes y testigos, aun cuando sólo en la medida en que se consideren necesarias para dictar sentencia, debiendo tenerse en cuenta el coste que todo ello conlleva a la hora de tomar una decisión al respecto. 
Como se indicó anteriormente, dicha vista oral puede ser acordada de oficio o a instancia de alguna de las partes. El primer supuesto normalmente acontecerá cuando el tribunal considere que la documentación que obra en las actuaciones no le permite entender debidamente la cuestión que enfrenta a las partes o que resulta conveniente para aclarar algunos extremos de la contienda. El segundo, cuando a la vista de lo alegado por el proponente en su escrito de alegaciones (recuérdese que, en ellos, las partes deben pronunciarse sobre distintos extremos: entre otros, sobre si consideran necesaria la celebración de una vista y, en caso afirmativo, los motivos por los que, a su entender, resulta pertinente), considere que su celebración puede ayudar a centrar los puntos objetos de debate.

En cualquier caso, la sentencia deberá dictarse en un plazo de treinta días, plazo que empezará a contarse a partir de la fecha en que concluyó el que se concedió previamente para recibir la respuesta del demandado o, en su caso, la contestación del actor a la reconvención o, en su defecto, para que se remitiese determinada información, se practicase la prueba propuesta y admitida o se celebrase la vista oral antedicha.

33. La sentencia, sea o no sea impugnada, será ejecutiva sin necesidad de que se constituya ninguna garantía (art. 15.1 del RPEEC).

34. En ella, el tribunal se pronunciará sobre las costas del proceso, que, con carácter general, se impondrán a quien pierda el litigio, si bien no se le condenará al pago de costas generadas innecesariamente o que no guarden proporción con el valor de la demanda (art. 16 del RPEEC), lo cual, habida cuenta su imprecisión, a buen seguro será objeto de numerosas controversias en el momento de su tasación y motivo de no pocas disputas.

\section{Posibles recursos contra la sentencia}

35. La posibilidad de recurrir la sentencia dictada en este proceso depende de la regulación que sobre esta cuestión prevea el ordenamiento interno del país en que siga el litigio (art. 17 del Reglamento).

36. España informó en su momento a la Comisión Europea que aceptaba que pudiese ser recurrida en apelación, la cual debía prepararse ante el tribunal que hubiese dictado la decisión impugnada $^{41}$, "anunciando la intención de recurrir la sentencia y especificando los pronunciamientos que se impugnan en el plazo de 5 días. Preparado que sea el recurso, el plazo para formalizar e interponer la apelación será de 20 días ante la Audiencia provincial correspondiente» ${ }^{42}$.

Poco después, sin embargo, el legislador español adoptó diversas medidas que incidían en esta materia, provocando cierta confusión.

Por un lado, aprobó la Ley 4/2011, de 24 de marzo, de modificación de la Ley 1/2000, de 7 de enero, de Enjuiciamiento Civil, para facilitar la aplicación en España de los procesos europeos monitorio y de escasa cuantía, en virtud de la cual se introdujo una nueva disposición final en dicho texto legislativo, la vigésima cuarta, en cuyo apartado 2 se indica que, en lo no regulado por el RPEEC, «Las cuestiones procesales no previstas en el Reglamento (CE) $n .^{\circ} 861 / 2007$ se regirán por lo previsto en esta Ley para el juicio verbal».

Por otro, pocos meses después, aprobó la Ley 37/2011, de 10 de octubre, de medidas de agilización procesal, en virtud de la cual suprimió el trámite de preparación de los recursos devolutivos y, en una decisión cuando menos polémica y discutible, reformó la posibilidad de recurrir en apelación las

\footnotetext{
${ }^{41}$ Según cual haya sido el objeto de la reclamación, dicho tribunal puede ser un Juzgado de Primera Instancia o un Juzgado de lo Mercantil, que son los órganos jurisdiccionales a los que corresponde el conocimiento en primera instancia del proceso europeo de escasa cuantía según la disposición final vigésima cuarta de la LEC de 2000.

${ }^{42}$ Así se indicaba en la «Información comunicada por los Estados miembros de conformidad con al artículo 25 del Reglamento (CE) no 861/2007 del Parlamento Europeo y del Consejo, de 11 de julio de 2007, por el que se establece un proceso europeo de escasa cuantía», que se encontraba disponible en su día en http://ec.europa.eu/justice_home/judicialatlascivil/html/ pdf/vers_consolidade_es_861.pdf.
} 
sentencias dictadas en primera instancia, disponiendo que todas ellas podían impugnarse ante un tribunal superior, salvo las dictadas «en los juicios verbales por razón de la cuantía cuando ésta no supere los 3.000 euros» (art. 455 de la LECiv). Lo que suscitó la duda de si con ello se impedía que pudiesen recurrirse en apelación las sentencias dictadas por un tribunal español al resolver un proceso europeo de escasa cuantía, que, en aquellos momentos, recuérdese, permitía decidir reclamaciones de hasta $2.000 €$, interrogante que, en su día, respondimos negativamente ${ }^{43}$.

37. Años después, el 16 de diciembre de 2015, el Parlamento Europeo y el Consejo de la Unión Europea aprobaron el Reglamento (UE) 2015/2421, en el que se elevó la cuantía que puede reclamarse a través de este proceso a la de 5.000€, lo que planteó un nuevo dilema: el de si, a la vista de todo lo antedicho, solo podían apelarse las sentencias dictadas en un proceso europeo de escasa cuantía cuando el valor económico del litigio, siendo superior a $3.000 €$, no excediere de $5.000 €$.

38. Si se piensa con detenimiento, enseguida se reparará que la cuestión es ciertamente discutible. Ya que, frente a quienes consideran que la misma ha de responderse afirmativamente, puede argumentarse la literalidad del propio art. 455.1 de la LECiv, precepto, que, tras significar una regla general: la de que las sentencias dictadas en toda clase de juicios -así como los autos definitivos y aquellos que expresamente señale la ley-son apelables, señala una única excepción referida a las sentencias dictadas en los juicios verbales por razón de la cuantía -que no por razón de la materia objeto del pleito- cuando ésta no supere los 3.000 euros. Los términos de la misma son claros y no admiten duda: sólo son irrecurribles las sentencias dictadas en aquellos juicios verbales que, habiéndose seguido en atención al valor del litigio, no superen la suma de 3.000 euros. Y si toda excepción es, por definición, una regla que se aparta de una condición general, es evidente que ha de interpretarse restrictivamente y, en consecuencia, que no puede -no debe- aplicarse a más supuestos de los expresamente previstos.

39. Por lo demás, esta solución, que es la que nos parece más razonable, parece asimismo la más adecuada. Al menos, por dos razones. En primer lugar, porque fija un mismo régimen de recursos, sea cual sea el valor económico del litigio, con la consiguiente seguridad jurídica que ello conlleva. Y, en segundo término, porque, como acabamos de señalar, lo que, en rigor, establece el art. 455.1 de la LECiv no es que en los juicios verbales no quepa recurrir ninguna sentencia cuando la cuantía del litigio no exceda de $3.000 €$, sino que no cabe hacerlo cuando se haya seguido dicho proceso declarativo por razón de la cuantía y esta no rebase dicho umbral, que es cosa distinta. Lo que, bien entendido, permite recurrir en apelación las sentencias dictadas en aquellos juicios verbales que se hayan seguido por razón de la materia, como sucede en el caso que nos ocupa, en el que, por decisión legislativa, en todo lo no regulado por el RPEEC, ha de estarse a lo previsto en la LECiv para el juicio verbal, sin que se refiera ninguna restricción a la regla general que ella misma dispone en orden a la impugnación de las sentencias dictadas en los juicios que se sigan por sus trámites.

40. Sin embargo, no es esta la conclusión por la que se ha decantado nuestro Gobierno, que, según se indica en la página web oficial de la Unión Europea ${ }^{44}$, en su día indicó a la Comisión de la Unión Europea que:

«No cabe recurso ordinario de apelación en los procesos de escasa cuantía en reclamaciones inferiores a 3.000 euros.

Para reclamaciones entre 3.000 y 5.000 euros es posible interponer recursos de apelación ante el propio tribunal que dictó la resolución que resolverá sobre su admisión y posterior remisión, para su resolución a la Audiencia Provincial. El plazo para interponer el recurso es de 20 días hábiles contados desde el día siguiente a la notificación de la sentencia».

${ }^{43}$ J. SigÜEnZA LÓPEZ, «El proceso europeo de escasa cuantía», en Cuestiones actuales de Derecho Patrimonial desde una perspectiva ítalo-española (obra coordinada por Juan Pablo Murga Fernández y Salvador Tomás Tomás), Ed. Tirant lo Blanch, Valencia, 2013, págs. 295-314.

${ }^{44} \mathrm{https}$ ://e-justice.europa.eu/content_small_claims-354-es-es.do?plang=es\&removebanner=true (última actualización: 25 de mayo de 2020). 
41. Dicha solución no nos parece acertada. Por las razones que acabamos de señalar, que nos parecen sólidas y fundadas, y, además, porque consideramos que no debe limitarse la posibilidad de impugnar una decisión judicial por criterios meramente cuantitativos, extraños por completo a los de la complejidad del caso, lo que supone asumir el presupuesto, a nuestro entender inaceptable, por cuanto que no es cierto, de que los asuntos de poca entidad económica son asuntos de escasa complejidad jurídica.

42. En cualquier caso, cuando sea posible recurrir la sentencia dictada en primera instancia, al notificarse la resolución, deberá indicarse a las partes que puede ser impugnada en apelación, el tribunal ante el que, en su caso, ha de interponerse el recurso, el plazo en que debe hacerse (cfr. art. 248.4 de la LOPJ) y el depósito dinerario que debe consignarse a tal efecto (50 euros, de conformidad con lo dispuesto en la disposición adicional decimoquinta de la LOPJ).

43. Por cuanto en nuestro sistema procesal no es posible interponer ningún recurso contra la sentencia dictada en primera instancia sin estar asistido de abogado y representado por procurador, se plantea la duda de si dicha prohibición también rige en el proceso europeo de escasa cuantía o en este, como excepción, se permite que pueda hacerlo por sí mismo. El Reglamento nada especifica al respecto, pero el hecho de que no contenga formulario alguno para poder presentar un posible recurso o para oponerse a él y que, en lo no previsto en dicha norma, haya de estarse a lo que disponga nuestro ordenamiento jurídico, abonan la tesis -ya avanzada al comienzo de este estudio- de que es preceptiva la intervención de dichos profesionales jurídicos para formular un recurso de apelación contra dicha sentencia, en los casos en que está permitido.

44. En virtud de este recurso puede pretenderse, con arreglo a los fundamentos de hecho y de derecho de las pretensiones formuladas ante el tribunal de primera instancia, que se revoque un auto o sentencia y que, en su lugar, se dicte otra resolución favorable a quien recurre, tras un nuevo examen de las actuaciones llevadas a cabo ante aquel tribunal y conforme a la prueba que, en los casos previstos en la LECiv, se practique ante el tribunal de apelación (art. 456.1 de dicho texto legal).

Actualmente, tras la modificación realizada por la Ley 37/2011, de 10 de octubre, de medidas de agilización procesal, a que antes nos referimos, no existe trámite de preparación de este recurso, por lo que directamente debe interponerse ante el tribunal que haya dictado la decisión que se ataca dentro del plazo de veinte días a contar desde el siguiente a aquel en que se hubiese notificado aquélla, de suerte que, al interponer el recurso, el apelante debe exponer las alegaciones en que fundamenta su impugnación, además de citar la resolución apelada y los pronunciamientos de los que discrepa (art. 458 de la LECiv).

Si el recurso se presenta dentro del citado plazo, el letrado de la Administración de Justicia adscrito al tribunal que haya conocido del pleito en primera instancia lo tendrá por interpuesto. Si a su juicio no se ha hecho así, lo pondrá en conocimiento del órgano jurisdiccional para que sea éste el que se pronuncie sobre su admisión, siendo posible recurrir en queja la eventual decisión de inadmitirlo a trámite ${ }^{45}$.

Admitida en su caso la interposición del recurso, el letrado de la Administración de Justicia dará traslado a las demás partes, emplazándolas por diez días para que presenten, ante el tribunal que dictó la resolución apelada, escrito de oposición al recurso o, en su caso, de impugnación de la sentencia en lo que ésta les resulte desfavorable, al que podrán adjuntar los documentos que sean admisibles en ese momento y en el que podrán pedir la práctica de aquellos medios de prueba que, de acuerdo con lo previsto en el art. 450 de la LECiv, puedan solicitarse.

A continuación, se dará traslado de dichos escritos al apelante principal para que, en el plazo de diez días, manifieste lo que tenga por conveniente sobre la admisibilidad de la impugnación y, en su caso, sobre los documentos aportados y las pruebas propuestas por el apelado.

Y posteriormente, transcurrido el citado plazo, y se hayan presentado o no los escritos de oposición o impugnación a que antes se hizo referencia, el letrado de la Administración de Justicia ordenará

\footnotetext{
${ }^{45}$ Contra la decisión de tener por interpuesto el recurso de apelación no cabe impugnación alguna, aun cuando podrá alegarse su inadmisibilidad en el trámite de oposición al recurso a que se refiere el art. 461 de la LEC de 2000 (art. 458.3 de dicho texto legal).
} 
que se remitan los autos al tribunal competente para resolver la apelación, emplazando a las partes para que comparezcan ante él en el plazo de diez días, declarándose desierto el recurso y firme la decisión impugnada si el apelante no comparece dentro del mismo.

Recibidos los autos en dicho tribunal, si se hubiesen aportado documentos o propuesto la práctica de prueba en segunda instancia, éste acordará lo que proceda sobre su admisión, practicándose en su caso en vista oral la que se considere pertinente, pudiéndose también celebrar vista, aunque no se haya propuesto prueba, o toda la propuesta fuera inadmitida, si así lo pide una de las partes o el tribunal la estima necesaria.

En cualquier caso, tenga lugar o no dicha vista oral, el tribunal competente para decidir la apelación resolverá mediante sentencia lo que proceda.

45. Sea como fuere, permítase o no recurso contra la sentencia que dicte el tribunal español que conozca en primer grado del proceso europeo de escasa cuantía, el art. 18 del RPEEC dispone que el demandado tiene derecho a solicitar la revisión de la misma en tres supuestos, siempre y cuando, eso sí, en todos ellos haya actuado con prontitud. En concreto, en los siguientes:

a) cuando el formulario de demanda o la citación a una vista oral no se hubiere notificado de forma que conste su recepción por el demandado;

b) cuando la notificación no se hubiese realizado con la suficiente antelación para permitirle preparar su defensa, sin que haya mediado responsabilidad por su parte;

c) o cuando no haya tenido oportunidad de oponerse a la demanda por causa de fuerza mayor o circunstancias extraordinarias ajenas a su responsabilidad.

46. Ello significa, por lo que a nuestro derecho hace, que, en función de cuándo tenga conocimiento el demandado de tales circunstancias, deberá alegarlas antes de que recaiga sentencia; en su caso, a través del pertinente recurso (art. 227.1 de la LECiv); y, finalmente, si no cabe hacerlo a través de recurso alguno, mediante el medio de impugnación más adecuado (audiencia al demandado rebelde; solicitud de nulidad de actuaciones; proceso de revisión de sentencia firme, según los casos).

47. Si, tras los trámites pertinentes, el órgano jurisdiccional rechaza la revisión por no considerar aplicables ninguno de los motivos antedichos, la sentencia se considerará firme.

Si por el contrario la considera procedente, la sentencia dictada en el proceso europeo de escasa cuantía será declarada nula y sin efecto (cfr. art. 18.2 del Reglamento).

\section{Reconocimiento y ejecución de sentencias en otro Estado de la Unión Europea que haya sus- crito el Reglamento comunitario 861/2007}

48. Una vez dictada, la sentencia tiene fuerza ejecutiva y, en consecuencia, puede ejecutarse, incluso si es recurrida, sin que su ejecución provisional pueda supeditarse en principio a que se preste garantía alguna ${ }^{46}$.

Además, puede ejecutarse en otro Estado obligado por el RPEEC sin necesidad de declaración de ejecutabilidad y sin que exista la posibilidad de oponerse a su reconocimiento: basta con que el tribunal que la haya dictado expida un certificado «utilizando el formulario estándar D, tal como figura en el anexo $I V »$ (art. 20.2 del RPEEC) para que pueda instarse su ejecución forzosa.

49. Sentado lo anterior, sin perjuicio de mayores especificaciones, puede apuntarse ahora que la ejecución de la sentencia dictada en un proceso de escasa cuantía se caracteriza por las siguientes notas:

\footnotetext{
${ }^{46}$ Con todo, en caso de recurso, a instancia de parte puede limitarse el procedimiento de ejecución a medidas cautelares; subordinar la ejecución a la constitución de una garantía; o incluso, en circunstancias excepcionales, suspender el citado procedimiento de ejecución (art. 23 del RPEEC).
} 
a) En primer lugar, porque se rige, al igual que el proceso de declaración, por lo dispuesto en el RPEEC y, con carácter subsidiario, por lo previsto en la legislación del Estado donde deba tener lugar ${ }^{47}$.

b) En segundo término, porque se encuentra condicionada por las mismas reglas a las que debe ajustarse la ejecución de las sentencias dictadas en el Estado obligado por el RPEEC en que deba desarrollarse ${ }^{48}$.

c) En tercera instancia, porque solo puede tener lugar a petición de parte, nunca de oficio.

d) En cuarto lugar, porque la solicitud de que se ejecute la sentencia debe ir acompañada de dos documentos: de una copia de dicha resolución que cumpla las condiciones de autenticidad necesarias; y de una copia del certificado de que la misma se ha dictado en un proceso europeo de escasa cuantía, traducida ${ }^{49}$, cuando proceda, en la lengua oficial del Estado en que deba cumplirse o, si éste tiene varias lenguas oficiales, o hubiere aceptado el uso de alguna de las lenguas oficiales de las instituciones de la Unión Europea para el proceso europeo de escasa cuantía, en cualquiera de ellas.

A este respecto procede apuntar que España ha aceptado expresamente que dicho certificado pueda estar redactado en lengua inglesa. Por lo que puede estar escrito tanto en castellano como en dicho idioma ${ }^{50}$.

e) En quinto término, porque la competencia para llevarla a cabo en España cuando la resolución se haya dictado en otro país de la Unión Europea corresponde al Juzgado de Primera Instancia del domicilio del demandado, que será también el órgano jurisdiccional al que corresponda decidir la denegación de la misma, a instancia de aquél, cuando corresponda, así como pronunciarse sobre «la limitación de la ejecución, la constitución de garantía o la suspensión del procedimiento de ejecución a que se refieren los artículos 22 y 23 del Reglamento (CE) $n^{\circ} 861 / 2007 »$ (disposición final vigésima cuarta, apartado 7, de la LECiv).

Como acaba de señalarse, dicha regla es aplicable cuando la sentencia que haya de ejecutarse en España haya sido dictada por un tribunal de otro país de la Unión Europea.

Cuando haya sido dictada sin embargo por un tribunal nacional, la competencia corresponde a los juzgados de primera instancia, salvo en los supuestos previstos en el artículo 86 ter 2 de la Ley Orgánica del Poder Judicial, en que se atribuye a los juzgados de lo mercantil ${ }^{51}$.

\footnotetext{
${ }^{47}$ A este respecto dispone nuestra legislación nacional que «Los procedimientos de ejecución en España de las sentencias dictadas en otros Estados miembros de la Unión Europea que pongan fin a un proceso europeo de escasa cuantía se regirán por lo dispuesto en esta Ley» y que «La tramitación de la denegación de la ejecución de la sentencia, así como la limitación de la ejecución, su suspensión o la constitución de garantía, se llevarán a cabo con arreglo a lo dispuesto en los artículo 556 y siguientes de esta Ley, sin que en ningún caso la sentencia pueda ser objeto de revisión en cuanto al fondo, y se resolverán mediante auto no susceptible de recurso» (disposición final vigésima cuarta, apartado 8, de la LECiv).

${ }^{48}$ Ello supone, por lo que hace a nuestro país, que el proceso de ejecución de un proceso europeo de escasa cuantía podrá acumularse a otro proceso de ejecución pendiente entre el mismo acreedor ejecutante y el mismo deudor ejecutado (art. 555 de la LECiv).

${ }^{49}$ En su caso, el contenido «del formulario D será traducido por una persona cualificada para realizar traducciones en uno de los Estados miembros» (art. 21.2 del RPEEC). A este respecto nuestra legislación dispone que, cuando deba ejecutarse en España una sentencia dictada en otro Estado miembro de la Unión Europea que ponga fin a un proceso europeo de escasa cuantía, «el demandante deberá presentar ante el Juzgado competente una traducción oficial al castellano o a la lengua oficial de la Comunidad Autónoma en cuyo territorio tengan lugar las actuaciones judiciales del certificado de dicha sentencia, certificada en la forma prevista en el apartado 2 del artículo 21 del Reglamento (CE) $n^{\circ} 861 / 2007$ »(disposición final vigésima cuarta, apartado 9, de la LECiv).

${ }^{50}$ Vide https://e-justice.europa.eu/content_small_claims-354-es-es.do?member=1

${ }^{51}$ Así se indica en la información facilitada por España a la Comisión de la Unión Europea, disponible en https://e-justice. europa.eu/content_small_claims-354-es-es.do?member=1\#a_111.

Es cierto que en ella no se especifica si dichos órganos jurisdiccionales solo tienen competencia para conocer de la ejecución de sentencias dictadas en procesos europeos de escasa cuantía que se hayan seguido en nuestro país o, si además de lo anterior, la tienen para la ejecución de sentencias dictadas en procesos seguidos en otro país miembro de la Unión Europea, pero no lo es menos que la LECiv se pronuncia de forma clara sobre la competencia en este último caso. Y, en consecuencia, que, en tanto no se modifique el criterio establecido al efecto en la disposición final vigésima cuarta, no cabe entender que los juzgados de lo mercantil tengan competencia en estos supuestos.
} 
f) Así mismo, porque no requiere que las partes estén representadas por un abogado u otro profesional del derecho durante su desarrollo. Pues, aunque el RPEEC no especifica si la regla de que no cabe exigir a las partes que actúen a través de un experto en leyes -vid. el Considerando $15 \mathrm{y}$ el art. 15 de dicha norma- se refiere tan solo a la fase de declaración o comprende también la de ejecución de la sentencia, un análisis detenido de su contenido obliga a concluir que afecta a ambas. Lo contrario se opondría a una visión amplia del proceso que analizamos y supondría una limitación carente de amparo normativo. Máxime cuando el RPEEC se refiere en todo momento a la parte que solicita la ejecución de la sentencia (vid. sus arts. 21, 22 y 23), significando que, «salvo los agentes con competencia en el proceso de ejecución» (art. 21.3 de dicha norma), no estará obligada a tener un representante autorizado o una dirección postal en el Estado en que se lleva a cabo la ejecución.

Ello no significa, sin embargo, que no sea conveniente, incluso muy recomendable, que se contraten los servicios de dichos profesionales. Pues su labor puede ser muy conveniente. De un lado, porque la ejecución precisa de importantes conocimientos técnicos de los que, como es natural, carecen los legos en derecho. De otro, porque el RPEEC no contiene formulario alguno que pueda servir de guía o ayuda a los justiciables sobre los trámites que se han de seguir para obtener la ejecución de la sentencia que les favorezca o, en su caso, para oponerse a la misma, lo que dificulta grandemente su labor.

Si se piensa con atención, enseguida se caerá en la cuenta de que estos argumentos permitirían defender la necesidad de utilizar los servicios de ambos expertos en la fase de ejecución. Sin embargo, como se ha dicho, no es esto lo que se prevé en el caso que nos ocupa. Y no solo por lo que se ha apuntado anteriormente, sino sobre todo porque el art. 539.1 de nuestra LECiv dispone con absoluta claridad que la regla de que el ejecutante y el ejecutado estén dirigidos por letrado y representados por procurador no resulta de aplicación cuando «se trate de la ejecución de resoluciones dictadas en procesos en que no sea preceptiva la intervención de dichos profesionales», que es precisamente lo que sucede en el supuesto que analizamos. Por lo que, como antes apuntamos, no resulta preceptiva su intervención en los procesos de ejecución de sentencias de procesos europeos de escasa cuantía que se sigan en España.

g) En séptimo lugar, por la prohibición de que el tribunal competente para ejecutar una sentencia dictada en un proceso europeo de escasa cuantía pueda revisar el fondo de la misma. Lo que no impide, claro está, que la persona frente a la que se dirija la ejecución pueda solicitar que se deniegue conforme a las reglas generales previstas en la legislación del Estado de ejecución (siempre y cuando, insisto, no se revise el fondo de la sentencia); singularmente, cuando la sentencia sea incompatible con otra dictada con anterioridad, siempre que se cumplan las siguientes tres condiciones: que la sentencia anterior tenga el mismo objeto y se refiera a las mismas partes; que dicha resolución se haya dictado en el Estado miembro de ejecución o cumpla las condiciones necesarias para ser reconocidas en este; y que no se hubiere alegado ni hubiera podido alegarse la incompatibilidad durante el proceso que se siguió en el Estado en que se dictó la sentencia.

h) Y, finalmente, por el hecho de que, no obstante la regla de que, una vez dictada, la sentencia tiene fuerza ejecutiva, en aquellos casos en que una de las partes la haya impugnado, dicha impugnación fuese todavía posible o se hubiere pedido su revisión, el tribunal o autoridad competente del Estado donde deba llevarse a cabo la ejecución podrá limitarla a la posible adopción de medidas cautelares; subordinar su inicio a que se constituya la garantía que se determine; o suspenderla, en circunstancias excepcionales, si lo solicita una de las partes y lo considera pertinente (vide el art. 25 del Reglamento).

\section{Cuestiones a considerar}

50. La realidad pone de manifiesto que, cuanto menor es la cuantía económica de la cuestión sobre la que se discute con otro, mayores son las dudas sobre si compensa dirimirla ante la jurisdicción, habida 
cuenta el coste económico -pero también de tiempo, esfuerzo y desgaste personal- que ello conlleva. Dichas dudas se incrementan notablemente si la disputa ha de suscitarse ante los tribunales de un país distinto al propio. Pues, a los anteriores inconvenientes, se suman otros, no menores, tales como la presumible necesidad de tener que expresarse en un idioma diferente al que suele utilizarse o la eventual exigencia de tener que contratar los servicios de un experto en las leyes de dicho país - un abogado-para que se defiendan debidamente los derechos e intereses de quien precisa la tutela judicial para que éstos sean reconocidos.

Conscientes de lo anterior, las instituciones comunitarias han regulado un proceso nuevo y autónomo que se ofrece a los justiciables como una alternativa a los procesos que regulan sus países de origen $^{52}$ con el que pretenden paliar dichas dificultades y en el que han optado decididamente por la escritura como forma de expresión de los actos procesales, en una decisión que -habida cuenta lo que se acaba de apuntar- parece acertada.

La decisión de regular un proceso predominantemente escrito, que en absoluto excluye por completo la oralidad, lo que explica los amplios poderes que se reconocen al órgano jurisdiccional en la dirección del proceso (que le permiten negar aquellas diligencias que considere innecesarias y poner de manifiesto eventuales omisiones en los escritos de alegaciones de las partes que, si éstas no subsanan en el plazo que se conceda al efecto, determinarán el rechazo de los mismos o su inadmisión a trámite) ${ }^{53}$, resulta así de la dificultad de articular un instrumento que puede adaptarse a las singularidades de los distintos países en que ha de aplicarse y de la necesidad de abaratar los costes que todo litigio lleva consigo, que se incrementarían notablemente si se hubiese optado por la oralidad y, en consecuencia, se hubiese exigido la presencia física de los contendientes.

La apuesta por la forma escrita de los actos procesales supone por tanto el reconocimiento de que es necesario adaptar el proceso -instrumento necesario para que los ciudadanos soliciten la tutela judicial que estimen necesaria en cada caso y para que los tribunales cumplan su función de juzgar y hacer cumplir lo juzgado- a las necesidades que en cada caso ha de satisfacer y que un proceso predominantemente escrito - que, por ello, por no desarrollarse totalmente de acuerdo con dicha forma, no excluye que determinados actos puedan tener lugar de forma oral- puede ser sumamente apto para resolver controversias ante los tribunales, sobre todo cuando las discrepancias son esencialmente jurídicas o el debate se fundamenta primordialmente sobre pruebas de carácter documental. Y, en cualquier caso, implica la adopción de una solución pragmática, aconsejada por el carácter transnacional de los litigios que a través suyo se han de resolver y los inconvenientes que antes reseñábamos, que, para terminar de completarse, opta por una tramitación simplificada y reducida en lo posible al intercambio de escritos y pruebas documentales.

51. Con todo, el éxito de este proceso en nuestro país está aún lejos de alcanzarse. Pues, como se apuntaba al comienzo de este estudio, un análisis de las resoluciones que se refieren en el buscador del Centro de Documentación Judicial de nuestro país revela que apenas se ha hecho uso de él en 53 supuestos, lo que hace una media de 3,85 asuntos por año desde la fecha en que el RPEEC entró en vigor.

El examen concienzudo de los mismos pone de manifiesto varios datos significativos.

En primer lugar, que en todos los casos han conocido de este proceso los juzgados de lo mercantil.

En segundo término, que todos ellos tienen su causa en contratos de transporte: 50 en contratos de transporte aéreo y 2 en contratos de transporte terrestre ${ }^{54}$, existiendo otro en el que se reclama una

${ }^{52}$ En parecidos términos: F. Martín Diz, «Protección procesal del crédito transfronterizo en la Unión Europea: propuesta de orden de embargo de activos bancarios», en Derecho Revista de Derecho Comunitario Europeo, Año no 12, núm. 30, 2008, pág. 390, quien destaca que se trata de un proceso alternativo a las posibilidades nacionales de protección del crédito, nunca sustitutivo ni excluyente de las mismas.

${ }^{53}$ En igual sentido: L. M. Bujosa VAdell, «Simplificación y oralidad en los litigios transfronterizos. El proceso europeo de escasa cuantía del Reglamento (CE) núm. 861/2007 del Parlamento Europeo y del Consejo», en Oralidad y escritura en un proceso civil eficiente [Coloquio de la Asociación Internacional de Derecho Procesal 2008] (obra editada por Federico Carpi y Manuel Ortells Ramos), Vol. 2, 2008, (Comunicaciones-Presentations), págs. 303-315.

${ }^{54}$ Vide las Sentencias del Juzgado de lo Mercantil núm. 3 de Pontevedra de 27 de septiembre de 2018 (ECLI:ES:JMPO:2018: 3089),Pte. Sr.BurguilloPozo; y del Juzgado de lo Mercantilnúm. 1 dePamplona de4 demarzo de2020(ECLI:ES:JMNA:2020:3850), Pte. Sra. Fernández Zabalegui. 
indemnización por daños y perjuicios, pero no es posible deducir con base en qué, ya que en la sentencia no se dan datos sobre el fundamento de la controversia ni la identidad del demandado, analizándose en ella si el allanamiento de este cumple los requisitos legales y si procede condenarle en $\operatorname{costas}^{55}$.

En tercer lugar, que la inmensa mayoría de ellos -42 de los 53 antes mencionados- se han suscitado ante los juzgados de lo mercantil de Palma de Mallorca ${ }^{56}$.

$\mathrm{Y}$, finalmente, que en muchos de ellos quien reclama es una empresa a la que los particulares han cedido su derecho, presumiblemente a cambio de un precio acordado.

52. Los anteriores datos, sumamente reveladores, obligan a reflexionar sobre el futuro de este proceso en orden al informe que, a más tardar el 15 de julio de 2022, la Comisión Europea ha de presentar al Parlamento Europeo, al Consejo y al Consejo Económico y Social Europeo sobre el funcionamiento del RPEEC ${ }^{57}$. Y también, claro está, sobre las medidas que podrían hacerlo más atractivo para los ciudadanos.

53. A tal efecto, y con dicha intención, nos permitimos hacer las siguientes propuestas y recomendaciones.

Primera. - Es preciso dar a conocer debidamente su existencia, toda vez que es un gran desconocido, incluso entre los profesionales del derecho, pues constituye un instrumento apto y eficaz para realizar determinadas reclamaciones. Por ejemplo, las que pretenden la devolución del precio satisfecho por la compra de un producto defectuoso realizada en un Estado afectado por el RPEEC distinto al propio o las que interesan el abono de servicios contratados y no pagados por un ciudadano europeo durante su estancia en otro país de la Unión al que sea de aplicación dicha norma. Una amplia campaña de difusión se hace pues imprescindible para dar a conocer sus bondades y favorecer el acceso a la justicia de los ciudadanos de la Unión.

Segunda. - Una forma de incentivar su uso sería la de suprimir la necesidad de abonar una tasa judicial en aquellos países que aún se exige.

Es cierto que en España no se requiere y que, pese a ello, apenas es utilizado. Pero ello es debido, a nuestro parecer, a la falta de incentivos para su uso y al desconocimiento entre los profesionales del derecho a que antes hicimos referencia. Por lo que la eliminación de esta traba podría hacerlo más atractivo en los países de la Unión Europea que aún la mantienen.

Tercera. - Parece conveniente incrementar el valor económico de la demanda en estos procesos. Es cierto que en 2015 se elevó a 5.000€ y que, sin duda, dicho umbral es más adecuado que el inicial de 2.000€. Pero entendemos que sería conveniente incrementarlo aún más, por ejemplo, a 7.500€, al menos

${ }^{55}$ Sentencia del Juzgado de lo Mercantil núm. 3 de Palma de Mallorca de 10 de agosto de 2018 (ECLI: ES:JMIB:2018:2876), Pte. Sr. Fernández González.

${ }^{56}$ Los restantes, salvo error mío, ante los juzgados de lo mercantil de Barcelona (2), Pontevedra (2), Oviedo (1), Madrid (2), Pamplona (1), Valencia (1) y Bilbao (2).

${ }^{57}$ Recuérdese a estos efectos que, según dispone el art. 28 del propio reglamento comunitario:

«1. A más tardar el 15 de julio de 2022, la Comisión presentará al Parlamento Europeo, al Consejo y al Comité Económico y Social Europeo un informe sobre el funcionamiento del presente Reglamento, que incluirá una evaluación sobre lo siguiente:

a) si resulta adecuado un incremento adicional del límite al que hace referencia el artículo 2, apartado 1, con el fin de alcanzar el objetivo del presente Reglamento de facilitar el acceso de los ciudadanos y las pequeñas y medianas empresas a la justicia en asuntos transfronterizos, $y$

b) si resulta adecuado extender el ámbito de aplicación del proceso europeo de escasa cuantía, en particular a las demandas relativas a retribuciones salariales, a fin de facilitar el acceso a la justicia de los trabajadores en litigios laborales transfronterizos con sus respectivos empleadores, previo examen de todas las repercusiones de dicha extensión.

Dicho informe irá acompañado, en su caso, de propuestas legislativas.

A tal efecto y a más tardar el 15 de julio de 2021, los Estados miembros facilitarán a la Comisión información sobre el número de demandas en el marco del proceso europeo de escasa cuantía, así como sobre el número de peticiones de ejecución de sentencias dictadas en el proceso europeo de escasa cuantía.

2. A más tardar el 15 de julio de 2019, la Comisión presentará al Parlamento Europeo, al Consejo y al Comité Económico y Social Europeo un informe sobre la difusión de información acerca del proceso europeo de escasa cuantía en los Estados miembros, y podrá proponer recomendaciones sobre cómo dar a conocer mejor dicho proceso». 
en aquellos casos en que el litigio se suscite entre empresas o personas jurídicas, a fin de animar a sus responsables a su utilización. Tiene el riesgo, es cierto, de que se constituyan empresas con el fin de comprar créditos litigiosos a particulares superiores a 5.000€. Pero entendemos que ello no supone un inconveniente que lo haga desaconsejable. Al revés, si se incrementa el número de procesos europeos de escasa cuantía por dicha razón, sería el momento de replantearse si dicho incremento no debe extenderse también a reclamaciones en las que el actor sea una persona física.

Cuarta. - Sería adecuado que su tramitación se regulase de forma más completa de lo que lo está actualmente, limitando así las muchas remisiones que se hacen en el RPEEC a las legislaciones de los Estados en los que es de aplicación dicha norma, ya que ello constituye un factor de complicación, sobre todo para los legos en derecho, que desanima recurrir al mismo.

Quinta. - Debería aclararse que la desestimación de la pretendido por el actor solo es posible en la sentencia. Y, por tanto, que cuando el Reglamento dispone que, en algunos casos, cabe rechazar la demanda, el legislador europeo se está refiriendo a su inadmisión a trámite o a que por parte de la autoridad competente se rechaza seguir tramitándola. En último extremo, sería positivo que en el Reglamento se dispusiera que en estos casos la decisión judicial debe ser la misma que, en supuestos semejantes, se acordaría en un pleito nacional.

Sexta. - Sería conveniente expresar, con la debida claridad, cómo han de prestar los Estados afectados por el RPEEC la asistencia práctica que se han comprometido a facilitar a quienes deseen hacer uso de este proceso para que puedan cumplimentar los formularios que en él se refieren (cfr. su art. 11). Ya que ello redundará, sin duda, en una mayor confianza en este proceso, en un mayor empleo del mismo y en un mejor desarrollo del procedimiento.

Séptima. - De igual modo, sería positivo que se indicará en dicha norma, con el máximo detalle posible, cómo han de cumplir los órganos jurisdiccionales el deber de informar a las partes sobre las cuestiones procesales que se hayan suscitado y deban resolverse, en aquellos casos en que ello sea preciso (cfr. el art. 12.2 del RPEEC), toda vez que, de lo contrario, dicho cometido puede quedar reducido a una mera declaración de intenciones, con los inconvenientes que ello conlleva.

Octava. - Igualmente, sería oportuno que se delimitase con la mayor exactitud posible en qué supuestos puede acordar de oficio el órgano jurisdiccional la celebración de una vista oral tras la presentación por las partes de sus respectivos escritos de alegaciones. Ya que, de lo contrario, si no se hace así, en algunos supuestos puede quedar en entredicho su necesaria imparcialidad, siendo preciso asimismo que se disponga que, en aquellos casos en que dicha vista deba tener lugar, deben cumplirse de la mejor manera posible las exigencias de contradicción, inmediación, concentración y publicidad.

En este punto sería asimismo conveniente que se especificase que la decisión de no celebrar una vista oral, cuando esta haya sido solicitada al menos por uno de los contendientes, debe estar debidamente fundada y razonada, a fin de que sea posible conocer, con el debido detalle, las razones que llevan al órgano jurisdiccional a no acordarla.

Novena. - Convendría considerar la posibilidad de que las partes pudiesen formular conclusiones por escrito tras la práctica de la prueba, en aquellos casos en que se acuerde, toda vez que ello podría coadyuvar a que fijasen con mayor precisión sus respectivas posiciones.

Décima. - El proceso europeo de escasa cuantía genera gastos para las partes (traducción de documentos, desembolsos de viaje para asistir a audiencias si no se pueden realizar por medios telemáticos, remuneración de testigos, etcétera) que sería bueno que se redujesen: quizá con ayudas estatales o de la propia Comisión de la Unión Europea, al menos durante los primeros años, para hacer más atractivo este instrumento.

Aunque la propuesta pueda parecer sorprendente, si se piensa bien, no es tan extraña. De hecho, entre nosotros, la Administración corre con ciertos gastos en el arbitraje de consumo, como el pago de determinadas pericias, a fin de poder alcanzar una resolución justa y equitativa sin coste para los consumidores y, en general, para las partes. ¿Por qué no hacer lo mismo en el proceso europeo de escasa cuantía?

Undécima. - Finalmente, creemos que sería conveniente que se dispusiera que la sentencia dictada en primera instancia en este proceso puede ser siempre impugnada ante un tribunal distinto y jerárquicamente superior al que haya firmado aquélla, habida cuenta que con ello se incrementarían las posibilidades de acierto, a la par que se limitarían los supuestos de posible error o equívoco judicial. 